\title{
Competition of two supply chains with different risk structures: applying market research option
}

\author{
A. Hafezalkotob ${ }^{*}$ and A. Makui
}

Department of Industrial Engineering, Iran University of Science \& Engineering, Tehran, Iran

\begin{tabular}{|c|c|}
\hline ARTICLEINFO & A B S TRACT \\
\hline $\begin{array}{l}\text { Article history: } \\
\text { Received } 30 \text { June } 2011 \\
\text { Received in revised form } \\
\text { September, 01, } 2011 \\
\text { Accepted 06 September } 2011 \\
\text { Available online } \\
\text { 17 September } 2011 \\
\text { Keywords: } \\
\text { Supply chain management } \\
\text { Game theory } \\
\text { Market research } \\
\text { Risk structure }\end{array}$ & $\begin{array}{l}\text { Demand uncertainty obliges all participants through a supply chain to make decisions under } \\
\text { uncertainty. These decisions extend across price, investment, production, and inventory } \\
\text { quantities. We take account of competition between two supply chains under demand } \\
\text { uncertainty. These chains internally are involved in vertical pricing competition; however, they } \\
\text { externally participate in horizontal pricing and service level competitions by offering a single- } \\
\text { type product to the market. Since firms may have various attitudes against demand uncertainty } \\
\text { and its related risks, different risk structures for competitive supply chains are considered. We } \\
\text { assume that risk-averse firms are able to decrease demand uncertainty by information gathered } \\
\text { from market research. For risk-averse participants in a chain, market research investment is an } \\
\text { appropriate ground for vertical coordination, which diminishes risk through a supply chain. } \\
\text { Optimal strategies based on game theory are obtained for different risk structures; furthermore, } \\
\text { for each structure the effects of risk sensitivity as well as market research efficiency on these } \\
\text { optimal strategies are investigated. Finally, we propose two scenarios for information sharing } \\
\text { between risk-averse participants. }\end{array}$ \\
\hline
\end{tabular}

\section{Introduction}

A supply chain (SC) can be stated as "a system of suppliers, manufacturers, distributors, retailers, and consumers where materials flow downstream from suppliers to customers and information flows in both directions" (Ganeshan et al., 1998). Independent firms constituting a SC frequently consider conflicting goals, which extend across pricing, purchasing, inventory, transportation, production, service, and other such functions (Kogan \& Tapiero, 2007). Two types of competition schema exist regarding to competitive supply chains: horizontal and vertical competitions. Vertical competition refers to conflicting goals within a chain's partners (e.g. pricing competition between manufacturer and its retailer), however horizontal competition is defined among the same types of companies with conflicting goals which may or may not belong to a single SC (Leng \& Parlar, 2005).

\footnotetext{
* Corresponding author. Tel.: +989121439946

E-mail: Hafezalkotob@iust.ac.ir (A. Hafezolkotob) 
Product price and service level offered by SCs are two significant factors affecting the purchasing decisions of customers in a large number of industries such as automotive, financial services, and insurance industries (Xiao \& Yang, 2008). In such industries, cutting product prices and investment for providing better services are two strategies, which could absorb the customers. However, from horizontal competition's point of view, market demand of a SC is not only affected from its own price and service level but also from the rival's chain price and service level.

In decision making about price and service level investment, often high uncertainty exists regarding to customers' behavior and their demand. Although investing in accurate forecasting and market research methods diminish this uncertainty, forecast errors cannot be omitted from the SCs decision making (Chopra \& Meindl, 2007). Uncertainty in demand brings about uncertainty in profits of all firms through a chain. The risk attitude of a firm determines the sensitivity towards profit or demand uncertainty. Risk-neutral firms are completely indifferent to risk involved profit uncertainty and they are only concerned about the expected profit. However, risk-averse firms avoid risk by minimizing profit uncertainty as well as maximizing the expected profit. Since, participants of a SC may have different attitudes towards risk, various risk structures can be considered for two competitive SCs such as symmetric and asymmetric risk structures. In symmetric risk structure, similar types of companies (e.g. both rival manufacturers) are risk-averse, and in asymmetric one, dissimilar types of companies such as one retailer and one manufacturer in rival SC, are risk-averse.

Vertical and horizontal competitions are influenced from risk attitude of each participant. In the case of vertical competition, Tsay (2002) argued that return policies are mechanisms by which a manufacturer can increase the retailer's order through converting his certain profit payoff to an uncertain one. Therefore, the manufacturer accepts exposure to risk and popular vernacular tends to label this as a "sharing" or "transfer" of risk. On the other hand, Xiao and Yang (2008) showed that risk sensitivity of retailers influences the optimal decisions of the rival chain as well as their manufacturer. According to this fact, a company may desire to reveal unreal risk sensitivity to dictate specific strategy to his partners and rivals. In section 5, we investigate vertical and horizontal competitions between two chains with different risk structures. Afterwards, the effects of risk attitude of each participant on optimal decisions in each structure are investigated.

Market research encompasses a wide range of qualitative methods and quantitative techniques for understanding attitude and behavior of customers. Data collection and data analyses reduce uncertainty over market and customers (Mariampolski, 2001). To the best of our knowledge, in the previous studies, manufacturers and retailers were considered inactive towards demand uncertainty, i.e. the uncertainty of market was a constant and exogenous parameter, which appears in model formulations. However, in the real world competitions, when participants have some sensitivity to risk, they may not be inactive to demand uncertainty. In section 5, we assume that by utilizing information gathered via market research investment, risk-averse participants are able to diminish market demand uncertainty. Market research investment highlights the significance of coordination. Since all risk-averse firms through a chain benefit from diminishing demand uncertainty, market research investment can be an appropriate ground for the vertical coordination.

The paper is organized as follows. In section 2, the related literature is reviewed. Section 3 includes a discussion of the problem and related notations. The basic model of vertical and horizontal competition with risk-averse participants is presented in section 4. The vertical and horizontal competitions are developed with considering market research option in section 5. In this section, different risk structures of SC as well as coordination in market research investment are investigated. 


\section{Literature review}

In the literature, several researches reviewed the game theory applications in modeling conflicting goals between participants of a SC (Cachon \& Netessine, 2003; He et al., 2007; Kogan \&Tapiero, 2007; Leng \& Parlar, 2005). Besides, competition and collaboration within a SC in a specific product market, there are some kinds of horizontal competition to attract final customers. Several papers considered vertical or horizontal competition models based on price and service level. Tsay and Agrawal (2000) investigated a one-manufacture and two-retailer SC, which offered a common product to customers. The competition between retailers was modeled based on a linear customer demand function of service level and retail-sale price, which each retailer offered to the market.

Bernstein and Federguen (2004) developed a stochastic inventory model for an oligopoly where demand was a function of all retailers' price and service levels. Three scenarios were studied in the paper: only price competition, simultaneous price and service level competition and two stage competition. They have shown that in each of these scenarios a Nash equilibrium of infinite-horizon stationary strategies exists under which each retailer adopts a stationary price, fill rate, and base-stock policy.

Bernstein and Fedegruen (2007) assumed a general model of two-echelon SCs with several competing retailers served by a common supplier. In the study, the demand of retailers is a stochastic function and depends on firms' prices as well as a measure of their service levels, e.g., the steadystate availability of the products. By applying three different demand functions, the equilibrium Nash price and service level were computed. Furthermore, Allon and Federgruen (2007) considered general market for competing service firms. The offered price and service level measured by customer waiting time differentiate firms from all other ones. They showed that the resulting queuing facility model yields equilibrium behavior depending on strategic choices of different firms.

Some papers regarded risk attitude towards risk sensitivity in SC interactions. Tsay and Agrawal (2000) argued the effect of different return policies on manufacturer-retailer relationship under various scenarios of relative strategic power. He discussed that in such a relationship, manufacturer or retailers should consider which of them could absorb risk better. By utilizing different return policies, the risk does not disappear, but merely shifts up or down between parties. Yang et al. (2009) developed a competition model for a SC with one supplier and two risk-averse retailers based on price, service level, and lot size. They investigated the effect of risk attitude of a retailer on his decisions as well as his rival retailer's decisions. They concluded that risk sensitivity of one retailer has a negative effect on his own decisions including retail price, service level, and lot size. The risk sensitivity of a partner affects decisions of other SCs as well. In the case of risk sensitivity of participant among multiple SCs, Xiao and Yang (2008) developed a price and service competition model of one-manufacturer and one-retailer chains to study the optimal decisions of the players under demand uncertainty. They analyzed the effects of the retailer risk sensitivity on the optimal strategies of the players, and the effect of investment efficiency of the retailer on the optimal price - service decisions of his rival, as well. Moreover, Xiao and Yang (2009) developed an information revelation mechanism model of a two-echelon SC facing an outside competitor to investigate the effect of the risk sharing rule on revelation mechanism under demand uncertainty where the risk sensitivity of the retailer is private information.

Our paper is closely related to Bernstein and Federgruen (2004), Tsay (2002) and Xiao and Yang(2009). However, our work is different from more comprehensive according to following aspects. Xiao and Yang (2009) only took risk sensitivity of retailers into account, but we consider various risk structures for two competitive SCs as different scenarios and we found out that responses to risk sensitivity depend on risk structures of both chains. Furthermore, in all scenarios, horizontal competition based on service level and price and vertical pricing competition are jointly considered. Finally, to the best of our knowledge, market research investment was not regarded in SC 
competitions models as a tool for diminishing uncertainty. Nevertheless, market research adds a new dimension to competitions framework between SCs and it can be a decent ground for coordination among risk-averse participants through a SC.

\section{Problem description and notation}

Two SCs are considered and each of them is comprised of two partners: one manufacturer and one retailer for offering a single type of product to the market. The interaction between manufacturer and retailer through a chain for determining transfer prices is called vertical pricing competition (Kogan $\&$ Tapiero, 2007). On the other hand, SCs compete for customers. Their offered products are partial substitutive and coefficient $d(0 \leq d \leq 1)$ represents substitutability status of products in the market. Retailers of both SCs are involved in price and service level competitions, which is referred as horizontal competition(s). Since the retailers or manufacturers may have various risk sensitivities towards demand uncertainty, it is assumed that they are able to invest in market research to gather information about customers' behavior and consequently decrease the demand uncertainty. Let $i$ represents $\mathrm{SC}$ and $M_{i}$ and $R_{i}$ denote manufacturer and retailer in $i$ th $\mathrm{SC}$. We consider the following assumptions, parameters, and variables.

\subsection{Assumptions}

1. The market demand is a linear combination of the price and service level offered by both retailers.

2. All parameters in the model have common knowledge for SCs partners, except demand constant levels $\left(\tilde{\alpha}_{i}\right)$ which are random variables with known parameters.

3. The variance of demand constant levels may decline by the information gathered from the market research.

4. The sequence of the game is as follows:

Stage 1: In each SC, manufacturer offers a wholesale price to the retailers over a given planning period of time. Furthermore, risk-averse manufacturer can invest in market research to decrease demand uncertainty.

Stage 2: The retailers in each SC decide on retail price as well as service level investment. Moreover, risk-averse retailers can diminish demand uncertainty by investing in market research. Retailers simultaneously present their products to the customers.

\subsection{Input parameters}

Supply chains are denoted by $i(i=1,2)$.

$\tilde{\alpha}_{i}$ the stochastic market based for retailer $i$ with mean $\bar{\alpha}_{i}>0$ and variance $\sigma_{i}^{2}$;

$\sigma_{0 i}^{2}$ the primary variance of the market based demand for retailer $i$, which refers to initial demand variance before market investment;

$c_{i}$ the unit production cost of manufacturer $i, \bar{\alpha}_{i} \geq c_{i}>0$;

$d$ the substitutability coefficient of the two products, $1>d>0$;

$\beta$ the demand sensitivity of one retailer to his own service level, $\beta>0$;

$\gamma$ the demand sensitivity of one retailer to his rival's service level, $\beta>\gamma>0$; 
$\lambda_{R_{i}}$ the constant absolute risk aversion (CARA) of retailer $i$ towards fluctuation of his own profit, which is defined in the Arrow-Pratt sense, $\lambda_{R_{i}} \geq 0$;

$\lambda_{M_{i}}$ the constant absolute risk aversion (CARA) of manufactureri towards fluctuation of his own profit, which is defined in the Arrow-Pratt sense, $\lambda_{M_{i}} \geq 0$;

$\tau_{R_{i}}$ the efficiency of market research investment by retailer $i$ in reducing the customer's demand uncertainty, $\tau_{R_{i}} \geq 0$;

$\tau_{M_{i}}$ the efficiency of the market research investment by manufacturer $i$ in reducing the customer's demand uncertainty, $\tau_{M_{i}} \geq 0$.

\subsection{Decision variables}

$w_{i} \quad$ the wholesale price of manufacturer in SCi offered to his retailer, $\left(w_{i} \geq c_{i}\right)$;

$m_{i} \quad$ the margin profit of retailer in SC $i$ from selling product to the customers, $\left(m_{i} \geq 0\right)$;

$M R_{R_{i}}$ the market research investment by retaileri, $\left(M R_{R_{i}} \geq 0\right)$;

$M R_{M_{j}}$ the market research investment by manufacturer $i,\left(M R_{M_{j}} \geq 0\right)$

$s_{i} \quad$ the service level of retailer $i,\left(s_{i} \geq 0\right)$.

Two important factors, which affect the market demand are retail price and service level (Xiao \& Yang, 2008, 2009). Since the retail-price of product $i$ is $p_{i}=m_{i}+w_{i}$, the retailer and manufacturer jointly influence the market demands of the SCs. Similar to Tsay and Agrawal (2000), Xiao and Yang (2008), we assume that retaileri encounters the market demand as follows:

$\tilde{q}_{i}=\tilde{a}_{i}-p_{i}+d p_{j}+\beta s_{i}-\gamma s_{j}, \quad i, j=1,2, \quad i \neq j$.

Eq.(1) states that the market demand of each retailer is an increasing function of his own service level and rival's price, but a decreasing function of his own price and rival's service level.

\section{Vertical and horizontal competition (The basic model)}

In each $\mathrm{SC}$, the manufacturer specifies wholesale price $\left(w_{i}\right)$ and the retailer determines retail margin ( $\left.m_{i}\right)$ as well as service level investment $\left(s_{i}\right)$. The manufacturer has ample capacity and the period is longer than the manufacturer's production lead time, which implies that the manufacturer is able to deliver on time any demand quantity announced by the retailer. Vertical competition refers to the non-cooperative pricing game between the manufacturer and his retailer; however, horizontal competition is related to the non-cooperative game based on service level and products price between two retailers in the market. Taking demand function (1) into account, the random profit functions of the retailer and manufacturer in $\mathrm{SC} i$ are as follows

$$
\tilde{\pi}_{M_{i}}\left(w_{i}\right)=\left(w_{i}-c_{i}\right)\left(\tilde{a}_{i}-\left(m_{i}+w_{i}\right)+d\left(m_{j}+w_{j}\right)+\beta s_{i}-\gamma s_{j}\right), \quad i, j=1,2, i \neq j,
$$


$\tilde{\pi}_{R_{i}}\left(m_{i}, s_{i}\right)=m_{i}\left(\tilde{a}_{i}-\left(m_{i}+w_{i}\right)+d\left(m_{j}+w_{j}\right)+\beta s_{i}-\gamma s_{j}\right)-\frac{1}{2} \eta_{i} s_{i}^{2}, \quad i, j=1,2, i \neq j$.

In the manufacturer profit function(2), $w_{i}-c_{i}$ is profit margin from producing and selling a unit of product to the retailer; therefore, Eq. (2) represents total profit of the manufacturer from $\tilde{q}_{i}$ product units. In similar manner, the first part of Eq. (3) characterizes the total profit of the retailer from $\tilde{q}_{i}$ product units. We assume that service level cost function of retailer $i$ is $\eta_{i} s_{i}^{2} / 2$; that is, improving service level has a diminishing effect on service level expenditure (Gilbert \& Cvsa, 2003; Tsay \& Agrawal, 2000; Xiao \& Yang, 2008\& 2009; Yang et al. 2009). Randomness of the market demand involves uncertainty in the profit functions. The manufacturer and retailer may have different risk attitudes towards this uncertainty. Risk-neutral retailers (manufacturers) are completely insensitive to profit fluctuations; however, risk-averse retailers (manufacturers) determine their strategies to reduce profit uncertainty. It is an undeniable fact that firms do care about risk, and different firms may care to different extents (Tsay, 2002). Both manufacturer and retailer can be risk-averse based on their individual preferences. Therefore, we investigate equilibrium condition when partners with different risk aversions behavior and incomplete information engage in a non-cooperative vertical game. Moreover, it is assumed that risk-averse retailers participate in a non-cooperative horizontal game in a market. Bar-Shira and Finkelshtain(1999) stated that using the utility function $\{E(\tilde{\pi})-\lambda \operatorname{Var}(\tilde{\pi})\}$ which raises the mean and reduces the variance is more robust than approaches based on the expected utility. Several researchers employed this utility function in modeling supply chain interactions (Monahan, 1987; Agrawal \& Seshadri, 2000; Gan et al., 2005; Wu et al., 2007; Xiao \& Yang, 2008). According to the mean-variance concept for Eqs.(2)and (3), the manufacturer and retailer assess the following utility functions

$$
\begin{aligned}
& u_{M_{i}}\left(\tilde{\pi}_{M_{i}}\left(w_{i}\right)\right)=E\left(\tilde{\pi}_{M_{i}}\left(w_{i}\right)\right)-\lambda_{M_{i}} \operatorname{Var}\left(\tilde{\pi}_{M_{i}}\left(w_{i}\right)\right), \quad i, j=1,2, i \neq j, \\
& u_{R_{i}}\left(\tilde{\pi}_{R_{i}}\left(m_{i}, s_{i}\right)\right)=E\left(\tilde{\pi}_{R_{i}}\left(m_{i}, s_{i}\right)\right)-\lambda_{R_{i}} \operatorname{Var}\left(\tilde{\pi}_{R_{i}}\left(m_{i}, s_{i}\right)\right), \quad i, j=1,2, i \neq j .
\end{aligned}
$$

In mean-variance concept of Eq. (4) and Eq. (5), $\lambda_{M_{i}}$ and $\lambda_{R_{i}}$ are constant relative risk aversions (CARA) which specify the risk attitude of the manufacturer and retailer towards uncertainty, respectively. $\lambda_{M_{i}}=0\left(\lambda_{R_{i}}=0\right)$ means that manufacturer (retailer) is risk-neutral; conversely, $\lambda_{M_{i}}>0$ $\left(\lambda_{R_{i}}>0\right)$ indicates risk-averse behavior and the higher the CARA, the more conservative the behavior will be. In this section, it is assumed that the variances of market demand are exogenous and constant parameters; However, the uncertainty of market demand can be diminished by the market research investment throughout section 5. From Eq. (4) and Eq. (5), we have

$$
\begin{aligned}
& u_{M_{i}}\left(\tilde{\pi}_{M_{i}}\left(w_{i}\right)\right)=\left(w_{i}-c_{i}\right)\left(\bar{a}_{i}-\left(m_{i}+w_{i}\right)+d\left(m_{j}+w_{j}\right)+\beta s_{i}-\gamma s_{j}\right)-\lambda_{M_{i}}\left(w_{i}-c_{i}\right)^{2} \sigma_{0 i}^{2}, i, j=1,2, i \neq j, \\
& u_{R_{i}}\left(\tilde{\pi}_{R_{i}}\left(m_{i}, s_{i}\right)\right)=m_{i}\left(\bar{a}_{i}-\left(m_{i}+w_{i}\right)+d\left(m_{j}+w_{j}\right)+\beta s_{i}-\gamma s_{j}\right)-\frac{1}{2} \eta_{i} s_{i}^{2}-\lambda_{M_{i}} m_{i}^{2} \sigma_{0 i}^{2}, i, j=1,2, i \neq j .
\end{aligned}
$$

Since $\partial^{2} u_{M_{i}}\left(\tilde{\pi}_{M_{i}}\left(w_{i}\right)\right) / \partial w_{i}^{2}=-2-2 \lambda_{M_{i}} \sigma_{0 i}{ }^{2}$, it follows that $u_{M_{i}}\left(\tilde{\pi}_{M_{i}}\left(w_{i}\right)\right)$ is a concave function on $w_{i}$. Moreover, Hessian matrix of $u_{R_{i}}\left(\tilde{\pi}_{R_{i}}\left(m_{i}, s_{i}\right)\right)$ is

$$
H_{R_{i}}=\left[\begin{array}{cc}
-2\left(1+\lambda_{R_{i}} \sigma_{0 i}^{2}\right) & \beta \\
\beta & -\eta_{i}
\end{array}\right], i=1,2 .
$$


The utility function $u_{R_{i}}\left(\tilde{\pi}_{R_{i}}\left(m_{i}, s_{i}\right)\right)$ is a concave function on $\left(m_{i}, s_{i}\right)$ if and only if Hessian matrix $H_{R_{i}}$ is negatively defined (Bazaraa et al., 2006). Assuming $B_{i}=2-\beta^{2} / \eta_{i}$ and $V_{i}=\gamma \beta / \eta_{i}-d$, proposition 1 clarifies the relationship between profit margins of the SC's partners in Nash equilibrium solution.

Proposition 1. If $B_{i}, B_{j}>0$, then Nash equilibrium solutions satisfy $K_{i} m_{i}^{*}=\left(w_{i}^{*}-c_{i}\right)$ where $K_{i}=\left(1+2 \lambda_{R_{i}} \sigma_{0 i}^{2}\right) /\left(1+2 \lambda_{M_{i}} \sigma_{0 i}^{2}\right)$. Therefore, we have

(i) $w_{i}^{*}-c_{i}=m_{i}^{*}$ if $\lambda_{M_{i}}=\lambda_{R_{i}}$,

(ii) $w_{i}^{*}-c_{i}<m_{i}^{*}$ if $\lambda_{M_{i}}<\lambda_{R_{i}}$,

(iii) $w_{i}^{*}-c_{i}>m_{i}^{*}$ if $\lambda_{M_{i}}>\lambda_{R_{i}}$.

Proofs of all propositions are given in Appendix A. It is immediately obvious from proposition 1 that in Nash equilibrium solution, the relationships between the profit margins of the manufacturer and retailer in each chain are independent of the rival chain's participants. Furthermore, if the retailer and manufacturer have equal sensitivity to risk (i.e. $\lambda_{M_{i}}=\lambda_{R_{i}}$ ), then their profit margins are equal. Conversely, if $\lambda_{M_{i}} \neq \lambda_{R_{i}}$, then each party who behaves more conservative has a lower profit margin. The condition $B_{i}>0$ states that the service level investment should not be too inexpensive; otherwise, i.e. $B_{i}<0$ brings about retailer $i$ excessively invests in service level which increases cost in inordinate manner. This assumption is compatible with Gilbert and Cvsa(2003) Tsay (2002), Tsay \& Agrawal (2000), Xiao \& Yang (2009), Yang et al. (2009); therefore, it is assumed that $B_{1}, B_{2}>0$ throughout this paper. The Nash equilibriums for Eq. (6) and Eq. (7) are given in proposition 2.

Proposition 2. In the vertical and horizontal competition between two SCs with risk-averse participants, if $B_{i}, B_{j} \geq 0$, then Nash equilibrium solution for profit margin of retailer $i(i=1,2)$ is

$$
m_{i}^{*}=\frac{\left(B_{j}+K_{j}+2 \lambda_{R_{j}} \sigma_{0 j}^{2}\right)\left(\bar{a}_{i}-c_{i}+d c_{j}\right)-\left(V_{j}-d K_{j}\right)\left(\bar{a}_{j}-c_{j}+d c_{i}\right)}{\left(B_{i}+K_{i}+2 \lambda_{R_{i}} \sigma_{0 i}^{2}\right)\left(B_{j}+K_{j}+2 \lambda_{R_{j}} \sigma_{0 j}^{2}\right)-\left(V_{i}-d K_{i}\right)\left(V_{j}-d K_{j}\right)},
$$

where $K_{i}=\left(1+2 \lambda_{R_{i}} \sigma_{0 i}^{2}\right) /\left(1+2 \lambda_{M_{i}} \sigma_{0 i}^{2}\right)$. Furthermore, the equilibrium solutions for service level investment and wholesale price are obtained from $s_{i}^{*}=\beta m_{i}^{*} / \eta_{i}$ and $w_{i}^{*}=K_{i} m_{i}^{*}+c_{i}$, respectively.

Retailer $i$ withdraws from competition, if $m_{i}^{*}<0$. Therefore, we assume $m_{i}^{*} \geq 0$ throughout this paper. It is obvious from Eq. (8) that CARA coefficients of all players affect the retailer's profit margin. The expected value of the market demand from retailer $i$ is obtained by substituting optimal decisions of proposition 2 into Eq. (1) which yields,

$$
E\left(\tilde{q}_{i}^{*}\right)=\bar{a}_{i}-c_{i}+d c_{j}-\left(B_{i}-1+K_{i}\right) m_{i}^{*}+\left(V_{j}-d K_{j}\right) m_{j}^{*}
$$

Furthermore, the expected profit of the manufacturer and retailer are $E\left(\tilde{\pi}_{M_{i}}\right)=K_{i} m_{i}^{*} E\left(\tilde{q}_{i}^{*}\right)$ and $E\left(\tilde{\pi}_{R_{i}}\right)=m_{i}^{*}\left(E\left(\tilde{q}_{i}^{*}\right)-\frac{\beta^{2}}{2 \eta_{i}} m_{i}^{*}\right)$, respectively. 


\section{Vertical and horizontal competition with market research option}

The demand uncertainty brings about serious problems for many companies, which extend across capacity limitations, uncertainty in production planning, inventory shortage or surplus, and profit fluctuation. Managers often look for formal marketing studies to produce insight into the market attitudes and buying behavior of the customers. Marketing research was about a \$28.9 billion industry globally in 2009, according to ESOMAR, the World Association of Opinion and Market Research Professionals. Koltler and Keller (2006) defined marketing research as a systematic design, collection, analysis, and reporting of data and findings relevant to a specific marketing situation facing a company. In other words, the results of market research strategy can decrease overall uncertainty towards demand of market (Koltler \& Keller, 2006). It may be unrealistic to assume riskaverse firms are inactive to this uncertainty. In many real cases, they diminish demand and profit uncertainty by investing in market research and effective forecasting methods.

In our research, three scenarios are considered with respect to market research investment. When retailers are risk-averse and manufacturers are risk-neutral, retailers may invest in the market research. Conversely, in the case of risk-neutral retailers and risk-averse manufacturers, manufactures may decide to invest in the market research. Finally, in the scenario of risk-averse retailers and manufacturers, they may collaboratively invest in the market research.

\subsection{Risk-averse retailers and risk-neutral manufacturers}

Retailers are frequently motivated to place initial orders long before the products are introduced to industries distinguished by short products life cycle such as fashion appeal, toys, and computers hardware (Yang et al., 2009). When products are introduced to the market and real demand is revealed, previous demand uncertainty often induces shortage and surpluses costs on retailers. Riskaverse retailers take this uncertainty into account and by investing in market research endeavor to decrease demand uncertainty. We assume that uncertainty of demand is constant when no market investment is made; however, the uncertainty diminishes as market research investment increases. Therefore, demand variance can be considered as a function of market research investment, which rationally has the following specifications

i) $\sigma_{i}^{2}=\sigma_{0 i}^{2} \geq 0$, When $M R_{R_{i}}=0$,

ii) $\partial \sigma_{i}^{2} / \partial M R_{R_{i}} \leq 0$,

iii) $\partial^{2} \sigma_{i}^{2} / \partial M R_{R_{i}}^{2} \leq 0$.

Different functions can be considered, which hold these relationships between demand variance and market research investment (such as linear, exponential, power, reciprocal or hyperbolic functions). We assume the function $\sigma_{i}^{2}=\sigma_{0 i}^{2} /\left(1+\tau_{R_{i}} M R_{R_{i}}\right)$, which holds the specification. However, other type of functions can be used as well. As it will be discussed subsequently, this function has no effect on concavity of retailer and manufacturer's utility functions. Coefficient $\tau_{R_{i}}$ represents market research efficiency of retailer $i$ in reducing demand uncertainty and the higher the coefficient $\tau_{R_{i}}$, the higher the efficiency of market research will be.

When retailers are risk-averse, they may invest in market research. Since risk-neutral manufacturers do not take demand uncertainty into account, they decline to participate in the market research investment. Therefore, the utility functions of manufacturer and retailer in chain $i$ are as follows 
$u_{M_{i}}\left(\tilde{\pi}_{M_{i}}\left(w_{i}\right)\right)=\left(w_{i}-c_{i}\right)\left(\bar{a}_{i}-\left(m_{i}+w_{i}\right)+d\left(m_{j}+w_{j}\right)+\beta s_{i}-\gamma s_{j}\right)$,

$u_{R_{i}}\left(\tilde{\pi}_{R_{i}}\left(m_{i}, s_{i}, M R_{R_{i}}\right)\right)=m_{i}\left(\bar{a}_{i}-\left(m_{i}+w_{i}\right)+d\left(m_{j}+w_{j}\right)+\beta s_{i}-\gamma s_{j}\right)-\frac{1}{2} \eta_{i} s_{i}^{2}-M R_{R_{i}}-\frac{\lambda_{R_{i}} m_{i}^{2} \sigma_{0 i}^{2}}{1+\tau_{R_{i}} M R_{R_{i}}}$.

Proposition 3 elucidates relationship between retailer and manufacturer profit margins in the Nash equilibrium solution.

Proposition 3. If $B_{i}, B_{j}>0$, then Nash equilibrium solutions satisfy $2 \sigma_{0 i} \sqrt{\lambda_{R_{i}} / \tau_{R_{i}}}+m_{i}^{*}=\left(w_{i}^{*}-c_{i}\right)$. Therefore, we have

(i) $w_{i}^{*}-c_{i}=m_{i}^{*}$ if $\lambda_{R_{i}}=0$,

(ii) $w_{i}^{*}-c_{i}>m_{i}^{*}$ if $\lambda_{R_{i}}>0$.

Proposition 3 gives us the following insights:

- In each SC, the relationship between the manufacturer and retailer margins is independent of rival chain's strategies.

- The risk-averse retailer has a lower margin profit than the risk-neutral manufacturer and this difference between profit margins increases as the retailer becomes more conservative. That is to say, risk-averse retailers sacrifice their margin profit to achieve higher level of certainty.

- Higher efficiency in the market research investment can diminish the reduction in retailers' profit margin, which reduce the demand uncertainty, simultaneously.

Proposition 4 gives the Nash equilibrium solution.

Proposition 4. In the vertical competition between two SCs with risk-averse retailers and risk-neutral manufactures, if $B_{i}, B_{j} \geq 0$, then Nash equilibrium solution for retailer $i$ 's margin $(i=1,2)$ is

$$
m_{i}^{*}=\frac{\left(B_{j}+1\right)\left[\bar{a}_{i}-c_{i}+d c_{j}-4 \sigma_{0 i} \sqrt{\frac{\lambda_{R_{i}}}{\tau_{R_{i}}}}+2 d \sigma_{0 j} \sqrt{\frac{\lambda_{R_{j}}}{\tau_{R_{j}}}}\right]-\left(V_{j}-d\right)\left[\bar{a}_{j}-c_{j}+d c_{i}-4 \sigma_{0 j} \sqrt{\frac{\lambda_{R_{j}}}{\tau_{R_{j}}}}+2 d \sigma_{0 i} \sqrt{\frac{\lambda_{R_{i}}}{\tau_{R_{i}}}}\right]}{\left(B_{i}+1\right)\left(B_{j}+1\right)-\left(V_{i}-d\right)\left(V_{j}-d\right)} .
$$

Moreover, optimal values for the service level, wholesale price, and market research investment are obtained from $s_{i}^{*}=\beta m_{i}^{*} / \eta_{i}, w_{i}^{*}=m_{i}^{*}+2 \sigma_{0 i} \sqrt{\lambda_{R_{i}} / \tau_{R_{i}}}+c_{i}$, and $M R_{R_{i}}^{*}=\left(m_{i}^{*} \sigma_{o i} \sqrt{\tau_{R_{i}} \lambda_{R_{i}}}-1\right) / \tau_{R_{i}}$, respectively.

Since we have $\sigma_{0 i}^{2} /\left(1+\tau_{R_{i}} M R_{R_{i}}^{*}\right) \leq \sigma_{0 i}^{2}$, market research investment by retailer $i$ declines uncertainty of demand; therefore, he absorbs the risk of profit fluctuations by investing in market research. In proposition 4, it is needed to assume that demand uncertainty is sufficiently high or retailer is riskaverse enough such that $\left(m_{i}^{*} \sigma_{o i} \sqrt{\tau_{R_{i}} \lambda_{R_{i}}}-1\right) / \tau_{R_{i}} \geq 0$, which guarantees that the market research investment to be a non-negative value. Market research investment is not desirable for the retailer, if $m_{i}^{*} \sigma_{o i} \sqrt{\tau_{R_{i}} \lambda_{R_{i}}}<1$; thus, he sets $M R_{R_{i}}^{*}=0$ and proposition 2 gives optimal solution. For instance, in the case of $\lambda_{R_{i}}=0$, retailer is risk-neutral, and $m_{i}^{*} \sigma_{o i} \sqrt{\tau_{R_{i}} \lambda_{R_{i}}}<1$ shows that he does not invest in market research.

It is straightforward from Eq. (12) that risk sensitivities of both retailers affect their profit margins. In part 1 of proposition 5, we investigate how risk sensitivity of a retailer influences the decisions of the 
retailer and his manufacturer. Furthermore, in part 2 of the proposition, the effects of risk sensitivity of the retailer on the decisions of his rival manufacturer and retailer are analyzed.

Proposition 5.Assume $\max \left\{d_{-}^{(1)}, 0\right\}<d<\min \left\{d_{+}^{(1)}, 1\right\}$. Then

1. $\partial m_{i} / \partial \lambda_{R_{i}}<0, \partial s_{i} / \partial \lambda_{R_{i}}<0$

$\partial w_{i} / \partial \lambda_{R_{i}}>0$, if $\max \left\{0, d_{-}^{(1)}, d_{-}^{(2)}\right\}<d<\min \left\{1, d_{+}^{(1)}, d_{+}^{(2)}\right\}$,

2. $\partial m_{i} / \partial \lambda_{R_{j}}<0, \partial w_{i} / \partial \lambda_{R_{j}}<0, \partial s_{i} / \partial \lambda_{R_{j}}<0$, if $d>2 \gamma \beta /\left(\eta_{j}+\beta^{2}\right)$,

$\partial m_{i} / \partial \lambda_{R_{j}}=0, \partial w_{i} / \partial \lambda_{R_{j}}=0, \partial s_{i} / \partial \lambda_{R_{j}}=0$, if $d=2 \gamma \beta /\left(\eta_{j}+\beta^{2}\right)$,

$\partial m_{i} / \partial \lambda_{R_{j}}>0, \partial w_{i} / \partial \lambda_{R_{j}}>0, \partial s_{i} / \partial \lambda_{R_{j}}>0$, if $d<2 \gamma \beta /\left(\eta_{j}+\beta^{2}\right)$,

where, $\quad d_{ \pm}^{(1)}=\frac{\gamma \beta}{4}\left(\frac{\eta_{i}+\eta_{j}}{\eta_{i} \eta_{j}}\right) \pm \frac{1}{4} \sqrt{\gamma^{2} \beta^{2}\left(\frac{\eta_{i}+\eta_{j}}{\eta_{i} \eta_{j}}\right)^{2}+4\left(\frac{\gamma \beta}{2}+\left(B_{i}+1\right)\left(B_{j}+1\right)\right)}$,

and

$d_{ \pm}^{(2)}=\frac{\gamma \beta}{4}\left(\frac{2 \eta_{i}+\eta_{j}}{\eta_{i} \eta_{j}}\right) \pm \frac{1}{4} \sqrt{\gamma^{2} \beta^{2}\left(\frac{2 \eta_{i}+\eta_{j}}{\eta_{i} \eta_{j}}\right)^{2}+4\left(\frac{\gamma \beta}{2}+\left(B_{i}-1\right)\left(B_{j}+1\right)\right)}$.

In this proposition, the behaviors of profit margin of retailers towards risk sensitivity are consistent with results of Xiao and Yang (2008), where only retailers were risk-averse. Proposition 5gives us the following perceptions:

- Service level and profit margin of a retailer usually decrease as he becomes more conservative. From the vertical competition's point of view, the more the risk sensitivity of a retailer, usually the higher the profit margin of a manufacturer will be.

- Service level and profit margins of the rival retailer and manufacturer decrease as the retailer behaves more conservative, if substitutability of products is sufficiently high. From the horizontal competition's point of view, it may give the retailer an incentive to declare risk sensitivity higher than his real risk sensitivity. Furthermore, from the vertical competition's point of view, revealing higher sensitivity by the retailer leads to higher profit margin for his manufacturer. The condition becomes contrary, if substitutability of product is sufficiently low.

- When substitutability of products is low enough, the manufacturer and retailer in a chain jointly decide to decrease profit margins as well as service level in response to conservative behavior of rival retailer. That is to say, price cutting is more efficient strategy as compared to raising service level. The situation becomes to the contrary, if substitutability be sufficiently high.

Market research efficiency can influence the vertical and horizontal equilibrium as well. It is straightforward to show that $\operatorname{sign}\left(\partial m_{i} / \partial \tau_{R_{i}}\right)=-\operatorname{sign}\left(\partial m_{i} / \partial \lambda_{R_{i}}\right)$ and $\operatorname{sign}\left(\partial m_{i} / \partial \tau_{R_{j}}\right)=-\operatorname{sign}\left(\partial m_{i} / \partial \lambda_{R_{j}}\right)$.

That is, the effect of market research efficiency on $m_{i}^{*}, s_{i}^{*}, m_{j}^{*}, w_{j}^{*}$, and $s_{j}^{*}$ equals to the inverse effect of risk sensitivity on these variables. Therefore, the related conclusions of risk sensitivity (in proposition 5) can also be extended for the effects of the market research efficiency on the variables.

\subsection{Risk-neutral retailers and risk-averse manufacturers}

Manufacturers are often involved in planning for production, capacity, and procurement long before the products are introduced to the market and the real product demand is revealed. Accordingly, 
several manufacturers are obligated to make decisions about procurement, price, capacity, production quantity, and investment based on the forecast for future demand. For instance, Dell orders PC components in anticipation of customer demand. Suppliers of Dell such as Intel and Intel's suppliers also need forecasts to determine their own production and inventory levels to response Dell orders in short time. Therefore, all manufacturing firms involved in Dell's SC have to make orders and production plans under demand uncertainty (Chopra \& Meindl, 2007).

Changing production capacities and inventory shortages and surpluses as well as unplanned procurements often inflict heavy costs on manufacturers; therefore, they may behave more conservative than their retailers. Contrary to section 5.1, in this section, we assume manufacturers are risk-averse and retailers are risk-neutral (i.e. $\lambda_{M_{i}}>0$ and $\lambda_{M_{i}}=0$ ). In this situation, the manufactures may invest in market research to reduce demand uncertainty and forecast errors; thus, the utility functions of manufacturer and retailer are as follows:

$$
\begin{aligned}
& u_{M_{i}}\left(\tilde{\pi}_{M_{i}}\left(w_{i}, M R_{M_{i}}\right)\right)=\left(w_{i}-c_{i}\right)\left(\bar{a}_{i}-\left(m_{i}+w_{i}\right)+d\left(m_{j}+w_{j}\right)+\beta s_{i}-\gamma s_{j}\right)-M R_{M_{i}}-\frac{\lambda_{M_{i}}\left(w_{i}-c_{i}\right)^{2} \sigma_{0 i}^{2}}{1+\tau_{M_{i}} M R_{M_{i}}}, \\
& u_{R_{i}}\left(\tilde{\pi}_{R_{i}}\left(m_{i}, s_{i}\right)\right)=m_{i}\left(\bar{a}_{i}-\left(m_{i}+w_{i}\right)+d\left(m_{j}+w_{j}\right)+\beta s_{i}-\gamma s_{j}\right)-\frac{1}{2} \eta_{i} s_{i}^{2} .
\end{aligned}
$$

Note that market research investment is now a decision variable of the manufacturer. Proposition 6 shed light on the relationship between profit margins of risk-neutral retailer and risk-averse manufacturer.

Proposition 6. If $B_{i}, B_{j}>0$, then Nash equilibrium solutions satisfy $m_{i}^{*}=\left(w_{i}^{*}-c_{i}\right)+2 \sigma_{0 i} \sqrt{\lambda_{M_{i}} / \tau_{M_{i}}}$. Therefore, we have

(i) $w_{i}^{*}-c_{i}=m_{i}^{*}$ if $\lambda_{M_{i}}=0$,

(ii) $w_{i}^{*}-c_{i}>m_{i}^{*}$ if $\lambda_{M_{i}}>0$.

Proposition 6 states that in each SC, risk-averse manufacturer has a lower margin with respect to riskneutral retailer and the difference increases as the manufacturer becomes more conservative. The manufacturers are able to improve this reduction in profit margin by applying more efficient market research methods. Additionally, it is straightforward that the relation between profit margins in SC $i$ is independent of the rival chain strategies. By comparing the results of this proposition and proposition 3 , we conclude that in vertical competition, each party who is risk-averse has a lower profit margin. This consequence is comparable with the results of proposition 1 where no market research was allowed. The first order condition for utility functions (13) and (14) yields the following Nash equilibrium.

Proposition 7. In vertical competition between two SCs with risk-neutral retailers and risk-averse manufactures, if $B_{i}, B_{j} \geq 0$, then Nash equilibrium solution for retailer's $i$ margin $(i=1,2)$ is

$$
m_{i}^{*}=\frac{\left(B_{j}+1\right)\left[\bar{a}_{i}-c_{i}+d c_{j}+2 \sigma_{0 i} \sqrt{\frac{\lambda_{M_{i}}}{\tau_{M_{i}}}}-2 d \sigma_{0 j} \sqrt{\frac{\lambda_{M_{j}}}{\tau_{M_{j}}}}\right]-\left(V_{j}-d\right)\left[\bar{a}_{j}-c_{j}+d c_{i}+2 \sigma_{0 j} \sqrt{\frac{\lambda_{M_{j}}}{\tau_{M_{j}}}}-2 d \sigma_{0 i} \sqrt{\frac{\lambda_{M_{i}}}{\tau_{M_{i}}}}\right]}{\left(B_{i}+1\right)\left(B_{j}+1\right)-\left(V_{i}-d\right)\left(V_{j}-d\right)}
$$

Furthermore, the optimal service level, market research investment, and wholesale price are obtained from $s_{i}^{*}=\beta m_{i}^{*} / \eta_{i}, M R_{M_{i}}^{*}=\left(\left(w_{i}^{*}-c_{i}\right) \sigma_{o i} \sqrt{\lambda_{M_{i}} \tau_{M_{i}}}-1\right) / \tau_{M_{i}}$, and $w_{i}^{*}=m_{i}^{*}-\sqrt{2 \lambda_{M_{i}} / \tau_{M_{i}}} \sigma_{0 i}+c_{i}$, respectively. 
Market research investment will be desirable for manufacture $i$, if he is adequately risk-averse or demand uncertainty is sufficiently high such that $\left(w_{i}^{*}-c_{i}\right) \sigma_{o i} \sqrt{\lambda_{M_{i}} \tau_{M_{i}}}>1$. In this situation, market research strategy diminishes profit uncertainty. Otherwise, i.e. $\left(w_{i}^{*}-c_{i}\right) \sigma_{o i} \sqrt{\lambda_{M_{i}} \tau_{M_{i}}}<1$, the manufacturer does not invest in market research and proposition 2 gives the equilibrium strategy. Proposition 8 investigates the behavior of the equilibrium with regard to risk sensitivity of the manufacturers.

Proposition 8. Let $\max \left\{d_{-}^{(1)}, 0\right\}<d<\min \left\{d_{+}^{(1)}, 1\right\}$, then we have

$$
\begin{aligned}
& \text { 1. } \partial m_{i} / \partial \lambda_{M_{i}}>0, \partial s_{i} / \partial \lambda_{M_{i}}>0, \text { if } B_{j}>-1-d\left(V_{j}-d\right), \\
& \partial w_{i} / \partial \lambda_{M_{i}}>0, \text { if } V_{i}\left(V_{j}-d\right)<B_{i}\left(B_{j}+1\right), \\
& \text { 2. } \partial m_{i} / \partial \lambda_{M_{j}}<0, \partial w_{i} / \partial \lambda_{M_{j}}<0, \partial s_{i} / \partial \lambda_{M_{j}}<0, \text { if } d>2 \gamma \beta /\left(\beta^{2}-\eta_{j}\right), \\
& \partial m_{i} / \partial \lambda_{M_{j}}=0, \partial w_{i} / \partial \lambda_{M_{j}}=0, \partial s_{i} / \partial \lambda_{M_{j}}=0, \text { if } d=2 \gamma \beta /\left(\beta^{2}-\eta_{j}\right), \\
& \partial m_{i} / \partial \lambda_{M_{j}}>0, \partial w_{i} / \partial \lambda_{M_{j}}>0, \partial s_{i} / \partial \lambda_{M_{j}}>0, \text { if } d<2 \gamma \beta /\left(\beta^{2}-\eta_{j}\right),
\end{aligned}
$$

where $d_{ \pm}^{(1)}$ was defined in proposition 5 .

- Since $B_{j}>-1-d\left(V_{j}-d\right)$ holds for $d<\sqrt{0.5}$ (or for $d>\sqrt{0.5}$ and $B_{j}>-1-d\left(V_{j}-d\right)$ ), an increase in conservative behavior of the manufacturer, usually increases the profit margin and service level of his retailer. Thus, the manufacturer may be desirous to reveal higher risk sensitivity than his real risk sensitivity to induce the retailer to boost his service level. Alternatively, the manufacturer may be willing to reveal lower risk sensitivity than the real risk sensitivity to persuade the retailer to cut his retail-sale price.

- Against changing risk sensitivity of the rival manufacturer, the manufacturer and his retailer make consistent decisions about profit margins. That is, when the rival manufacturer becomes increasingly risk-averse, profit margin of the manufacturer and retailer, as well as service level of the retailer decline, if substitutability of products is sufficiently high. Therefore, from the horizontal competition's point of view, the manufacture may be willing to declare risk sensitivity more than his actual risk sensitivity to enjoy service level competitive advantages. The situation becomes to the contrary, if substitutability be sufficiently low.

- In SC responses to changing risk sensitivity of a rival manufacturer, price cutting and declining service level are consistent strategies. In other words, when price cutting is more efficient response, it should be supplemented by lower service level, and vice versa.

Since we know $\operatorname{sign}\left(\partial m_{i} / \partial \tau_{M_{i}}\right)=-\operatorname{sign}\left(\partial m_{i} / \partial \lambda_{M_{i}}\right)$ and $\operatorname{sign}\left(\partial m_{i} / \partial \tau_{M_{j}}\right)=-\operatorname{sign}\left(\partial m_{i} / \partial \lambda_{M_{j}}\right)$, the impacts of market research efficiency on $m_{i}^{*}, s_{i}^{*}, m_{j}^{*}, w_{j}^{*}$, and $s_{j}^{*}$ are obtained from inversing signs of derivatives of this variables with respect to risk sensitivity parameter, respectively. Accordingly, the related consequences can be extended for the effects of market research on optimal solution as well.

\subsection{Horizontal competition between chains with asymmetric risk structures}

Asymmetric risk structure implies that in one chain only retailer is risk-averse and in another only manufacturer is risk-averse. Therefore, horizontal competition model between these chains can be considered as a combination of models presented in sections 5.1 and 5.2. In order to clarify the 
attitude of participants towards risk, we introduce two superscripts in this section include $n$ and $a$ for risk-neutral and risk-averse players, respectively.

Without loss of generality, suppose that $\mathrm{SC} i$ consists of a risk-neutral manufacturer and a risk-averse retailer, and $\mathrm{SC} j$ adversely includes a risk-averse manufacturer and a risk-neutral retailer. Due to conservativeness of the retailer in chain $i$, he/she may be interested in investing in market research. Consequently, mean-variance value functions of random profits for partners in chain $i$ are as follows,

$$
\begin{aligned}
& u_{M_{i}^{n}}\left(\tilde{\pi}_{M_{i}^{n}}\left(w_{i}^{n}\right)\right)=\left(w_{i}^{n}-c_{i}\right)\left(\overline{a_{i}}-\left(m_{i}^{a}+w_{i}^{n}\right)+d\left(m_{j}^{n}+w_{j}^{a}\right)+\beta s_{i}^{a}-\gamma s_{j}^{n}\right), \\
& u_{R_{i}^{a}}\left(\tilde{\pi}_{R_{i}^{a}}\left(m_{i}^{a}, s_{i}^{a}, M R_{R_{i}^{a}}\right)\right)=m_{i}^{a}\left(\bar{a}_{i}-\left(m_{i}^{a}+w_{i}^{n}\right)+d\left(m_{j}^{n}+w_{j}^{a}\right)+\beta s_{i}^{a}-\gamma s_{j}^{n}\right)-\frac{1}{2} \eta_{i}\left(s_{i}^{a}\right)^{2}-M R_{R_{i}^{a}}-\frac{\lambda_{R_{i}}\left(m_{i}^{a}\right)^{2} \sigma_{0 i}^{2}}{1+\tau_{R_{i}} M R_{R_{i}^{a}}^{a}} .
\end{aligned}
$$

Furthermore, market research investment may be desired by the manufacturer in chain $j$. Thus, mean-variance value functions of random profits for partners in chain $j$ are as follows

$$
\begin{aligned}
& u_{M_{j}^{a}}\left(\tilde{\pi}_{M_{j}^{a}}\left(w_{j}^{a}, M R_{M_{j}^{a}}\right)\right)=\left(w_{j}^{a}-c_{j}\right)\left(\bar{a}_{j}-\left(m_{j}^{n}+w_{j}^{a}\right)+d\left(m_{i}^{a}+w_{i}^{n}\right)+\beta s_{j}^{n}-\gamma s_{i}^{a}\right)-M R_{M_{j}^{a}}-\frac{\lambda_{M_{j}}\left(w_{j}^{a}-c_{j}\right)^{2} \sigma_{0 j}^{2}}{1+\tau_{M_{j}} M R_{M_{j}^{a}}}, \\
& u_{R_{j}^{n}}\left(\tilde{\pi}_{R_{j}^{n}}\left(m_{j}^{n}, s_{j}^{n}\right)\right)=m_{j}^{n}\left(\bar{a}_{j}-\left(m_{j}^{n}+w_{j}^{a}\right)+d\left(m_{i}^{a}+w_{i}^{n}\right)+\beta s_{j}^{n}-\gamma s_{i}^{a}\right)-\frac{1}{2} \eta_{j}\left(s_{j}^{n}\right)^{2} .
\end{aligned}
$$

Proposition 9 illuminates the connection between profit margins of the manufacturer and the retailer in both chains.

Proposition 9. If $B_{i}, B_{j}>0$, then Nash equilibrium solutions satisfy $m_{i}^{a^{*}}+2 \sigma_{0 i} \sqrt{\lambda_{R_{i}} / \tau_{R_{i}}}=\left(w_{i}^{n^{*}}-c_{i}\right)$, and $m_{j}^{n^{*}}=\left(w_{j}^{a^{*}}-c_{j}\right)+2 \sigma_{0 j} \sqrt{\lambda_{M_{j}} / \tau_{M_{j}}}$.

Therefore, in the vertical competition between the manufacturer and retailer, conservative partner always has lower profit margin and the difference between margins becomes more considerable as CARA parameter increases. The relationship between profit margins in one chain is independent of risk structure and sensitivity of the rival chain. These results are compatible with proposition 3 and 6 .

Proposition 10. In a vertical competition between two SCs with asymmetric risk structures, if $B_{i}, B_{j} \geq 0$, then Nash equilibrium solutions for retailers margin are

$$
\begin{aligned}
& m_{i}^{a^{*}}=\frac{\left(B_{j}+1\right)\left[\bar{a}_{i}-c_{i}+d c_{j}-4 \sigma_{0 i} \sqrt{\frac{\lambda_{R_{i}}}{\tau_{R_{i}}}}-2 d \sigma_{0 j} \sqrt{\frac{\lambda_{M_{j}}}{\tau_{M_{j}}}}\right]-\left(V_{j}-d\right)\left[\bar{a}_{j}-c_{j}+d c_{i}+2 \sigma_{0 j} \sqrt{\frac{\lambda_{M_{j}}}{\tau_{M_{j}}}}+2 d \sigma_{0 i} \sqrt{\frac{\lambda_{R_{i}}}{\tau_{R_{i}}}}\right]}{\left(B_{i}+1\right)\left(B_{j}+1\right)-\left(V_{i}-d\right)\left(V_{j}-d\right)}, \\
& m_{j}^{n^{*}}=\frac{\left(B_{i}+1\right)\left[\bar{a}_{j}-c_{j}+d c_{i}+2 \sigma_{0 j} \sqrt{\frac{\lambda_{M_{j}}}{\tau_{M_{j}}}}+2 d \sigma_{0 i} \sqrt{\frac{\lambda_{R_{i}}}{\tau_{R_{i}}}}\right]-\left(V_{i}-d\right)\left[\bar{a}_{i}-c_{i}+d c_{j}-4 \sigma_{0 i} \sqrt{\frac{\lambda_{R_{i}}}{\tau_{R_{i}}}}-2 d \sigma_{0 j} \sqrt{\frac{\lambda_{M_{j}}}{\tau_{M_{j}}}}\right]}{\left(B_{i}+1\right)\left(B_{j}+1\right)-\left(V_{i}-d\right)\left(V_{j}-d\right)} .
\end{aligned}
$$

Moreover, other variables are obtained from $w_{i}^{n}=m_{i}^{a}+2 \sigma_{0 i} \sqrt{\lambda_{R_{i}} / \tau_{R_{i}}}+c_{i}, w_{j}^{a}=m_{j}^{n}-2 \sigma_{0 j} \sqrt{\lambda_{M_{j}} / \tau_{M_{j}}}+c_{j}$, $s_{i}^{a}=\beta m_{i}^{a} / \eta_{i}, s_{j}^{n}=\beta m_{j}^{n} / \eta_{j}, M R_{R_{i}}^{a}=\left(m_{i}^{a} \sigma_{0 i} \sqrt{\tau_{R_{i}} \lambda_{R_{i}}}-1\right) / \tau_{R_{i}}$, and $M R_{M_{j}}^{a}=\left(\left(w_{j}^{a}-c_{j}\right) \sigma_{0 j} \sqrt{\tau_{M_{j}} \lambda_{M_{j}}}-1\right) / \tau_{M_{j}}$.

The market research investment will be desirable for the retailer in chain $i$, and the manufacturer in chain $j$, if $m_{i}^{a} \sigma_{0 i} \sqrt{\tau_{R_{i}} \lambda_{R_{i}}}>1$ and $\left(w_{i}^{a^{*}}-c_{i}\right) \sigma_{o i} \sqrt{\lambda_{M_{i}} \tau_{M_{i}}}>1$, respectively. Otherwise, the manufacturer 
and retailer do not invest in market research and proposition 2 provides the equilibrium strategies. The expected market demand from the retailers are achieved from substituting the optimal decisions of proposition (10) into Eq. (1) which yields,

$$
\begin{aligned}
& E\left(\tilde{q}_{i}^{*}\right)=\bar{a}_{i}-c_{i}+d c_{j}-B_{i} m_{i}^{a^{*}}-\left(V_{j}-d\right) m_{j}^{n^{*}}-2\left(\sigma_{0 i} \sqrt{\lambda_{R_{i}} / \tau_{R_{i}}}+d \sigma_{0 j} \sqrt{\lambda_{M_{j}} / \tau_{M_{j}}}\right) \\
& E\left(\tilde{q}_{j}^{*}\right)=\bar{a}_{j}-c_{j}+d c_{i}-B_{j} m_{j}^{a^{*}}-\left(V_{i}-d\right) m_{i}^{n^{*}}+2\left(\sigma_{0 j} \sqrt{\lambda_{M_{j}} / \tau_{M_{j}}}+d \sigma_{0 i} \sqrt{\lambda_{R_{i}} / \tau_{R_{i}}}\right)
\end{aligned}
$$

Similarly, the expected profits of partners are obtained from substituting the optimal decisions of proposition (10) into mean values of functions (16)-(19), which results in

$$
\begin{aligned}
& E\left(\tilde{\pi}_{M_{i}^{n}}\right)=\left(m_{i}^{a^{*}}+2 \sigma_{0 i} \sqrt{\lambda_{R_{i}} / \tau_{R_{i}}}\right) E\left(\tilde{q}_{i}^{*}\right), \\
& E\left(\tilde{\pi}_{R_{i}^{a}}\right)=m_{i}^{a^{*}}\left(E\left(\tilde{q}_{i}^{*}\right)-\beta^{2} m_{i}^{a^{*}} / 2 \eta_{i}-\sigma_{0 i} \sqrt{\lambda_{R_{i}} / \tau_{R_{i}}}\right)-1 / \tau_{R_{i}} \\
& E\left(\tilde{\pi}_{M_{j}^{a}}\right)=\left(m_{j}^{n^{*}}-2 \sigma_{0 j} \sqrt{\lambda_{M_{j}} / \tau_{M_{j}}}\right)\left(E\left(\tilde{q}_{j}^{*}\right)-\sigma_{0 j} \sqrt{\lambda_{M_{j}} / \tau_{M_{j}}}\right)-1 / \tau_{M_{j}} \\
& E\left(\tilde{\pi}_{R_{j}^{n}}\right)=m_{j}^{n}\left(E\left(\tilde{q}_{j}^{*}\right)-\beta^{2} m_{j}^{n^{*}} / 2 \eta_{j}\right) .
\end{aligned}
$$

Proposition 11 analyzes the sensitivity of the equilibrium between these two chains with respect to the CARA coefficients.

Proposition 11. Assume $\max \left\{d_{-}^{(1)}, 0\right\}<d<\min \left\{d_{+}^{(1)}, 1\right\}$, then we have

$$
\begin{aligned}
& 1 . \partial m_{i}^{a^{*}} / \partial \lambda_{R_{i}}<0, \partial s_{i}^{a^{*}} / \partial \lambda_{R_{i}}<0, \\
& \partial w_{i}^{n^{*}} / \partial \lambda_{R_{i}}>0, \text { if }\left(B_{i}-1\right)\left(B_{j}+1\right)>V_{i}\left(V_{j}-d\right), \\
& \partial m_{j}^{n^{*}} / \partial \lambda_{M_{i}}>0, \partial s_{j}^{n^{*}} / \partial \lambda_{M_{i}}>0, \text { if } B_{j}>-1-d\left(V_{j}-d\right), \\
& \partial w_{j}^{a^{*}} / \partial \lambda_{M_{i}}<0, \text { if } B_{j}\left(B_{i}+1\right)>V_{i}\left(V_{j}-d\right), \\
& 2 . \partial m_{i}^{a^{*}} / \partial \lambda_{M_{j}}<0, \partial w_{i}^{n^{*}} / \partial \lambda_{M_{j}}<0, \partial s_{i}^{a^{*}} / \partial \lambda_{M_{j}}<0, \text { if } \beta^{2} \leq \eta_{j}, \\
& \partial m_{i}^{a^{*}} / \partial \lambda_{M_{j}}<0, \partial w_{i}^{n^{*}} / \partial \lambda_{M_{j}}<0, \partial s_{i}^{a^{*}} / \partial \lambda_{M_{j}}<0, \text { if } \beta^{2}>\eta_{j} \text { and } d>\gamma \beta /\left(\beta^{2}-\eta_{j}\right), \\
& \partial m_{i}^{a^{*}} / \partial \lambda_{M_{j}}=0, \partial w_{i}^{n^{*}} / \partial \lambda_{M_{j}}=0, \partial s_{i}^{a^{*}} / \partial \lambda_{M_{j}}=0, \text { if } \beta^{2}>\eta_{j} \text { and } d=\gamma \beta /\left(\beta^{2}-\eta_{j}\right), \\
& \partial m_{i}^{a^{*}} / \partial \lambda_{M_{j}}>0, \partial w_{i}^{n^{*}} / \partial \lambda_{M_{j}}>0, \partial s_{i}^{a^{*}} / \partial \lambda_{M_{j}}>0, \text { if } \beta^{2}>\eta_{j} \text { and } d<\gamma \beta /\left(\beta^{2}-\eta_{j}\right), \\
& \partial m_{j}^{n^{*}} / \partial \lambda_{R_{i}}>0, \partial w_{j}^{a^{*}} / \partial \lambda_{R_{i}}>0, \partial s_{j}^{n^{*}} / \partial \lambda_{R_{i}}>0, \text { if } d<2 \gamma \beta /\left(\beta^{2}+\eta_{i}\right), \\
& \partial m_{j}^{n^{*}} / \partial \lambda_{R_{i}}=0, \partial w_{j}^{a^{*}} / \partial \lambda_{R_{i}}=0, \partial s_{j}^{n^{*}} / \partial \lambda_{R_{i}}=0, \text { if } d=2 \gamma \beta /\left(\beta^{2}+\eta_{i}\right), \\
& \partial m_{j}^{n^{*}} / \partial \lambda_{R_{i}}<0, \partial w_{j}^{a^{*}} / \partial \lambda_{R_{i}}<0, \partial s_{j}^{n^{*}} / \partial \lambda_{R_{i}}<0, \text { if } d>2 \gamma \beta /\left(\beta^{2}+\eta_{i}\right) .
\end{aligned}
$$


Part 1 of the proposition explores changes in strategies from the vertical competition's point of view. However, in part 2, the effects of risk sensitivity on horizontal competition are investigated. This proposition gives us the following perceptions

- In SC with risk-averse retailer, profit margin and service level of the retailer usually decline as he behaves more conservative. Nevertheless, in SC with risk-averse manufacturer, profit margin and service level of the retailer generally increase while his manufacturer becomes more conservative. As a result, the manufacturer by revealing more conservative behavior to his retailer can induce him to increase service level and product price. Adversely, manufacturer can engage his retailer to decrease service level as well as product price by behaving lesser conservative.

- From the horizontal competition's point of view, in each SC, responsive strategies of the manufacturer and retailer to the rival's risk-sensitivity are consistent. Furthermore, service level reaction of the retailer is consistent with price reaction. For instance, price cutting strategy towards risk sensitivity of rival chain (whoever rival manufacturer or rival retailer) should be compensated by lower service level. Both manufacturer and retailer support the price cutting strategy by diminishing profit margins.

- Responses of the chain with risk-averse retailer towards risk attitude of the rival manufacture are as follows. When $\beta^{2}>\eta_{j}$ and substitutability is sufficiently high, the manufacturer and retailer react to excessive conservative behavior of the rival manufacturer by lowering profit margins and service level. Consequently, the rival manufacturer may pretend to be more conservative, if he would like to enjoy lower chain's service level and product price. Vice versa, if $\beta^{2}>\eta_{j}$ and substitutability is sufficiently low.

- Reactions of the chain with risk-averse manufacturer towards risk attitude of rival retailer are as follows. Excessive risk-sensitivity behavior of the rival retailer will be responded with lower service level as well as profit margins by the manufacturer and his retailer, if substitutability is high enough. Accordingly, rival risk-averse retailer may exhibit himself more conservative to benefit from reductions in service level and profit margins of the manufacturer and retailer. Vice versa, if substitutability is low enough.

Now, we numerically illustrate the effects of risk sensitivities of participants on the optimal strategies and expected profits. Moreover, the effects of market research efficiency on variance of profits are investigated as well. For simplicity, we assume identical parameters for both chains as follows

$$
\bar{a}_{1}=\bar{a}_{2}=10, \sigma_{01}=\sigma_{02}=2, \eta_{1}=\eta_{2}=c_{1}=c_{2}=1, \gamma=0.6, \beta=1, \tau_{R_{1}}=\tau_{M_{2}}=1 \text {, and } \lambda_{R_{1}}=\lambda_{M_{2}}=0.1 \text {. }
$$

From $B_{1}=B_{2}=1$ and $V_{1}=V_{2}=0.6-d$, we know that both value functions (16) and (17) are concave functions; furthermore, we have $d_{-}^{(1)}=-0.7$ and $d_{+}^{(1)}=1.3$. That is to say, denominators of optimal profit margins of retailers in functions (20) and (21) are positive values for each substitution parameter $0 \leq d \leq 1$. Table 1 illustrates the effects of risk sensitivities on optimal retail-sales prices and whole-sales prices. For $d=0.5$, we have $\left(B_{1}-1\right)\left(B_{2}+1\right)>V_{1}\left(V_{2}-d\right), \quad B_{2}>-1-d\left(V_{2}-d\right)$, and $B_{j}\left(B_{i}+1\right)>V_{i}\left(V_{j}-d\right)$. From the vertical competition's point of view, it is obvious from proposition 11 as well as Table 1 that $\partial m_{1}^{a^{*}} / \partial \lambda_{R_{1}}<0, \partial w_{1}^{n^{*}} / \partial \lambda_{R_{1}}>0, \partial m_{2}^{n^{*}} / \partial \lambda_{M_{1}}>0$, and $\partial w_{2}^{a^{*}} / \partial \lambda_{M_{1}}<0$. Moreover, for $d=0.5$, we know that $\beta^{2} \leq \eta_{2}$ and $d<2 \gamma \beta /\left(\beta^{2}+\eta_{1}\right)$. From the horizontal competition's point of view, it is straightforward from proposition 11 and Table 1 that $\partial m_{1}^{a^{*}} / \partial \lambda_{M_{2}}<0, \partial w_{1}^{n^{*}} / \partial \lambda_{M_{2}}<0$, $\partial m_{2}^{n^{*}} / \partial \lambda_{R_{1}}>0$, and $\partial w_{2}^{a^{*}} / \partial \lambda_{R_{1}}>0$. The effects of the market research efficiency on strategies of SCs are demonstrated in Table 2. Generally, the effects of market research efficiency on the strategies are contrast to the CARA effects stated in Table 1. It is obvious from Table 2 that for each risk-averse participant in chains, the market research investment decreases when he uses higher efficient market 
research methods. Additionally, variances of profits of risk-averse participants decline as they take advantage of higher efficient market research methods. In other words, they can better absorb the risk of the business by using more efficient methods for the market research.

\section{Table 1}

Optimal retail-sales prices and whole-sales prices with respect to risk sensitivities (for $\tau_{R_{1}}=\tau_{M_{2}}=1$ and $d=0.5$ )

\begin{tabular}{llllllllll}
\hline$\lambda_{R_{1}}$ & $\lambda_{M_{2}}$ & $m_{1}^{a^{*}}$ & $w_{1}^{n^{*}}$ & $m_{2}^{n^{*}}$ & $w_{2}^{a^{*}}$ & $E\left(\tilde{\pi}_{M_{1}^{n}}\right)$ & $E\left(\tilde{\pi}_{R_{1}^{a}}\right)$ & $E\left(\tilde{\pi}_{M_{2}^{a}}\right)$ & $E\left(\tilde{\pi}_{R_{2}^{n}}\right)$ \\
\hline 0.1 & 0.1 & 4.49 & 6.57 & 6.60 & 6.33 & 33.10 & 11.91 & 30.80 & 21.76 \\
0.1 & 0.5 & 4.24 & 6.51 & 7.33 & 5.50 & 30.34 & 10.69 & 25.62 & 26.85 \\
0.1 & 1 & 4.06 & 6.33 & 7.88 & 4.88 & 28.36 & 9.81 & 21.80 & 31.03 \\
0.5 & 0.1 & 2.94 & 6.76 & 6.67 & 6.41 & 33.29 & 7.48 & 31.72 & 22.30 \\
0.5 & 0.5 & 2.70 & 6.53 & 7.41 & 5.58 & 30.52 & 6.45 & 29.48 & 27.46 \\
0.5 & 1 & 2.51 & 6.34 & 7.96 & 4.96 & 28.54 & 5.71 & 22.60 & 31.68 \\
1 & 0.1 & 1.78 & 6.78 & 6.74 & 6.47 & 33.43 & 4.15 & 32.42 & 22.71 \\
1 & 0.5 & 1.54 & 6.54 & 7.47 & 5.64 & 30.66 & 3.26 & 27.13 & 27.91 \\
1 & 1 & 1.35 & 6.35 & 8.02 & 5.02 & 28.67 & 2.63 & 23.21 & 32.17 \\
\hline
\end{tabular}

Table 2

Optimal retail-sales prices and whole-sales prices with respect to market research efficiencies $\left(\lambda_{R_{1}}=\lambda_{M_{2}}=0.1\right.$ and $d=0.5)$

\begin{tabular}{lllllllllll}
\hline$\tau_{R_{1}}$ & $\tau_{M_{2}}$ & $m_{1}^{a^{*}}$ & $w_{1}^{n^{*}}$ & $m_{2}^{n^{*}}$ & $w_{2}^{a^{*}}$ & $M R_{R_{1}}^{a}$ & $M_{M_{2}}^{a}$ & $\operatorname{Var}\left(\tilde{\pi}_{R_{1}^{a}}\right)$ & $\operatorname{Var}\left(\tilde{\pi}_{M_{2}^{a}}\right)$ \\
\hline 1 & 1 & 4.49 & 6.75 & 6.60 & 6.33 & 1.84 & 3.17 & 2.84 & 2.73 \\
1 & 1.5 & 4.52 & 6.79 & 6.49 & 6.45 & 1.86 & 2.68 & 2.86 & 2.37 \\
1 & 2 & 4.55 & 6.82 & 6.42 & 6.53 & 1.88 & 2.37 & 2.88 & 2.13 \\
1.5 & 1 & 4.72 & 6.75 & 6.58 & 6.32 & 1.77 & 3.16 & 2.44 & 2.72 \\
1.5 & 1.5 & 4.75 & 6.79 & 6.48 & 6.44 & 1.78 & 2.68 & 2.46 & 2.36 \\
1.5 & 2 & 4.77 & 6.81 & 6.41 & 6.51 & 1.80 & 2.36 & 2.47 & 2.12 \\
2 & 1 & 4.85 & 6.75 & 6.58 & 6.31 & 1.67 & 3.16 & 2.17 & 2.71 \\
2 & 1.5 & 4.89 & 6.79 & 6.46 & 6.43 & 1.69 & 2.67 & 2.19 & 2.36 \\
2 & 2 & 4.91 & 6.81 & 6.40 & 6.51 & 1.70 & 2.36 & 2.20 & 2.12 \\
\hline
\end{tabular}

\subsection{Risk-averse manufacturers and retailers (coordination to obtain market information)}

Generally, vertical competitions negatively affect the SCs. On the one hand, the retailer orders less; on the other hand, the retail price goes up, accordingly profit margins shrink (Kogan \&Tapiero, 2007). When partners of SC are sensitive to uncertainty of demand, the market research investment can be an appropriate ground for the vertical coordination, which diminishes risks of all partners through a chain. On the opposite side, in the case of in coordination, the manufacturer and his retailer decide to separately invest in the market research, which may deteriorate the effects of vertical competition. Among various scenarios for coordination based on the market research, we propose two scenarios; discounting for market information and fixed fee-full coordination.

Since retailer usually has superior access to the market, in the first scenario, we assume that he takes up investing in the market research. The information of customers obtained from the market research can diminish uncertainty over market demand; hence, it is also valuable for the manufacturer who behaves conservative. Consequently, the manufacturer may desire to reach the true market information by offering appropriate discount to the retailer. In other words, the risk-averse manufacturer will sacrifice a specific part of his profit margin to achieve market information and absorb risk of the business. We name this contract as discounting for market information. Suppose that $r_{i},\left(0<r_{i}<w_{i}-c_{i}\right)$, is the least discount which the retailer is satisfied to reveal the true market information to his manufacturer. Discount $r_{i}$ is an exogenous parameter identified by a contract or 
bargaining process. If participants in both competitive chains pursue discounting contracts for the market information (with discount rate $r_{i}$ ), the resulting model for $i, j=1,2, i \neq j$ is as follows

$$
\begin{aligned}
& u_{M_{i}}\left(\tilde{\pi}_{M_{i}}\left(w_{i} \mid r_{i}\right)\right)=\left(w_{i}-c_{i}-r_{i}\right)\left(\bar{a}_{i}-\left(m_{i}+w_{i}\right)+d\left(m_{j}+w_{j}\right)+\beta s_{i}-\gamma s_{j}\right)-\frac{\lambda_{M_{i}}\left(w_{i}-c_{i}-r_{i}\right)^{2} \sigma_{0 i}^{2}}{1+\tau_{R_{i}} M R_{R_{i}}}, \\
& u_{R_{i}}\left(\tilde{\pi}_{R_{i}}\left(m_{i}, s_{i}, M R_{R_{i}}\right)\right)=\left(m_{i}+r_{i}\right)\left(\bar{a}_{i}-\left(m_{i}+w_{i}\right)+d\left(m_{j}+w_{j}\right)+\beta s_{i}-\gamma s_{j}\right)-\frac{1}{2} \eta_{i} s_{i}^{2}-M R_{R_{i}}-\frac{\lambda_{R_{i}}\left(m_{i}+r_{i}\right)^{2} \sigma_{0 i}^{2}}{1+\tau_{R_{i}} M R_{R_{i}}} .
\end{aligned}
$$

It is straightforward to show that $u_{M_{i}}\left(\tilde{\pi}_{M_{i}}\left(w_{i}\right)\right)$ is a concave function on $w_{i}$. Furthermore, similar to proof of proposition 3, it follows that $u_{R_{i}}\left(\tilde{\pi}_{R_{i}}\left(m_{i}, s_{i}, M R_{R_{i}}\right)\right)$ is a concave function on $\left(m_{i}, s_{i}, M R_{R_{i}}\right)$, if $B_{i}>0$. Therefore, differentiating Eq. (28) with respect to $w_{i}$ as well as differentiating Eq. (29) with respect to $m_{i}, s_{i}$, and $M R_{R_{i}}$ result in a Nash equilibrium. After some manipulations of the derivatives similar to proof of proposition 3 , the following equations for $i, j=1,2, i \neq j$ are obtained:

$$
\begin{aligned}
& \left(m_{i}+r_{i}\right)\left[\left(B_{i}-1\right) m_{i}+V_{j} m_{j}+2 w_{i}-d w_{j}-\bar{a}_{i}-c_{i}-r_{i}\right]+\left(w_{i}-c_{i}-r_{i}\right) \frac{2 \lambda_{M_{i}} \sigma_{0 i}}{\sqrt{\lambda_{R_{i}} \tau_{R_{i}}}}=0, \\
& B_{i} m_{i}+V_{j} m_{j}+w_{i}-d w_{j}-\bar{a}_{i}+r_{i}+2 \sqrt{\frac{\lambda_{R_{i}}}{\tau_{R_{i}}}} \sigma_{0 i}=0 .
\end{aligned}
$$

Eq. (30) and Eq. (31) constitute a nonlinear system of equations which can numerically be solved for $m_{1}, m_{2}, w_{1}$, and $w_{2}$.

In the scenario of fixed fee and full coordination, it is assumed that the manufacturer is the leader of the SC and the retailer invests in market research. The manufacturer sets $w_{i}=c_{i}$, but charges the retailer a fixed fee. In this manner, the manufacturer can regulate his share in the total chain profit without a special contract. In fixed fee and full coordination scenario, not only the negative effect of vertical competition because of the well-known double margination effect is mitigated (Kogan \&Tapiero, 2007), but the manufacturer is able to coordinate in market research investment by charging his retailer a fair fee (i.e. with considering discount). Assume $p_{i}=m_{i}+w_{i}$ is retail-sales price of retailer $i$. If participants in both chains take up the scenario of fixed fee and full coordination, value functions of the retaileri will be as follows

$$
u_{R_{i}}\left(\tilde{\pi}_{R_{i}}\left(p_{i}, s_{i}, M R_{R_{i}}\right)\right)=\left(p_{i}-c_{i}\right)\left(\bar{a}_{i}-p_{i}+d p_{j}+\beta s_{i}-\gamma s_{j}\right)-\frac{1}{2} \eta_{i} s_{i}^{2}-M R_{R_{i}}-\frac{\lambda_{R_{i}}\left(p_{i}-c_{i}\right)^{2} \sigma_{0 i}^{2}}{1+\tau_{R_{i}} M R_{R_{i}}} .
$$

Akin to the proof of proposition 3, it is uncomplicated to show that $u_{R_{i}}\left(\tilde{\pi}_{R_{i}}\left(p_{i}, s_{i}, M R_{R_{i}}\right)\right)$ is a concave function on $\left(m_{i}, s_{i}, M R_{R_{i}}\right)$, if $B_{i}>0$. Therefore, the first order conditions of $u_{R_{i}}$ and $u_{R_{j}}$ yield a Nash equilibrium solution. After some simplification of the derivatives similar to the proof of proposition 3 , the following equation for $i, j=1,2, i \neq j$ is achieved:

$$
B_{i} p_{i}+V_{j} p_{j}=\bar{a}_{i}+c_{i}-2 \sqrt{\frac{\lambda_{R_{i}}}{\tau_{R_{i}}}} \sigma_{0 i}
$$


Solving the system of Eq. (33) for $p_{i}$ and $p_{j}$ results in the following optimal retail-sales price of retailer $i$

$$
p_{i}^{*}=\frac{B_{j}\left(\bar{a}_{i}+c_{i}-2 \sqrt{\frac{\lambda_{R_{i}}}{\tau_{R_{i}}}} \sigma_{0 i}\right)-V_{i}\left(\bar{a}_{j}+c_{j}-2 \sqrt{\frac{\lambda_{R_{j}}}{\tau_{R_{j}}}} \sigma_{0 j}\right)}{B_{i} B_{j}-V_{i} V_{j}}, i, j=1,2, i \neq j .
$$

Furthermore, the optimal service level and market research investment of retailer $i$ are obtained from $s_{i}^{*}=\beta p_{i}^{*} / \eta_{i}$ and $M R_{R_{i}}^{*}=\left(p_{i}^{*} \sigma_{0 i} \sqrt{\tau_{R_{i}} \lambda_{R_{i}}}-1\right) / \tau_{R_{i}}$, respectively.

Now, we investigate the optimal wholesale price of the risk-averse manufacturer. It is obvious that both the retailer and the manufacturer have positive profit margins, if $c_{i}<w_{i}<p_{i}^{*}$. Given the retailers responses to the retail price, service level, and market research, the risk-sensitive manufacturer $i$ maximizes the following mean-variance utility function

$u_{M_{i}}\left(\tilde{\pi}_{M_{i}}\left(w_{i} \mid p_{i}^{*}, p_{j}^{*}, s_{i}^{*}, s_{j}^{*}, M R_{R_{i}}^{*}\right)\right)=\left(w_{i}-c_{i}\right)\left(\bar{a}_{i}-\left(p_{i}^{*}\right)+d\left(p_{j}^{*}\right)+\beta s_{i}^{*}-\gamma s_{j}^{*}\right)-\frac{\lambda_{M_{i}}\left(w_{i}-c_{i}\right)^{2} \sigma_{0 i}^{*}}{1+\tau_{R_{i}} M R_{R_{i}}^{*}}$.

By substituting $s_{i}^{*}=\beta p_{i}^{*} / \eta_{i}, s_{j}^{*}=\beta p_{j}^{*} / \eta_{j}$, and $M R_{R_{i}}^{*}=\left(p_{i}^{*} \sigma_{0 i} \sqrt{\tau_{R_{i}} \lambda_{R_{i}}}-1\right) / \tau_{R_{i}}$ into Eq. (35), we have

$u_{M_{i}}\left(\tilde{\pi}_{M_{i}}\left(w_{i} \mid p_{i}^{*}, p_{j}^{*}\right)\right)=\left(w_{i}-c_{i}\right)\left(\bar{a}_{i}-\left(B_{i}-1\right) p_{i}^{*}+V_{j} p_{j}^{*}\right)-\frac{\lambda_{M_{i}}\left(w_{i}-c_{i}\right)^{2} \sigma_{0 i}}{\sqrt{\lambda_{R_{i}}} p_{i}^{*}}$.

$u_{M_{i}}\left(\tilde{\pi}_{M_{i}}\left(w_{i} \mid p_{i}^{*}, p_{j}^{*}\right)\right)$ is a concave function on $w_{i}$; therefore, the ideal whole-sale price $\left(w_{i}^{+}\right)$is obtained from the first order condition as follows

$w_{i}^{+}=\frac{\sqrt{\lambda_{R_{i}}} p_{i}^{*}}{2 \lambda_{M_{i}} \sigma_{0 i}}\left(\bar{a}_{i}-\left(B_{i}-1\right) p_{i}^{*}+V_{j} p_{j}^{*}\right)+c_{i}$.

If $w_{i}^{+}>p_{i}^{*}$, then Eq. Error! Reference source not found. is an increasing function of $w_{i}$ in the interval $\left[c_{i}, p_{i}^{*}\right]$. Therefore, the optimal $w^{*}$ occurs at the highest price, which is possible for the manufacturer to charge the retailer. Otherwise, if $c_{i}<w_{i}^{+}<p_{i}^{*}$, then Eq. Error! Reference source not found. is an increasing function of $w_{i}$ in the interval $\left[c_{i}, w_{i}^{+}\right]$, but a decreasing function in $\left[w_{i}^{+}, p_{i}^{*}\right]$. Accordingly, wholesales price higher than $w_{i}^{+}$is not desirable for the manufacturer and the optimal wholesale price is the highest price in the interval $\left[c_{i}, w_{i}^{+}\right]$that he is able to charge the retailer.

\section{Conclusion}

In this research, the competition between two supply chains along with the internal competitions through each chain have been considered. Since demand uncertainty brings about risk for participants in supply chains, risk-averse participants are able to invest in market research to diminish this uncertainty. We developed various risk structures for chains, and in each structure, the effect of risk 
sensitivity of each firm on other firms decisions was investigated. We found that revealing unreal risk sensitivity as well as using efficient market research methods help a risk-averse firm to induce specific strategy to his partner and the rival chain. Finally, two different scenarios for coordination in market research investment and sharing demand information through a supply chain were presented.

\section{Appendix A}

\section{Proof of proposition 1}

From Hessian matrix $H_{R_{i}}$, we know that $u_{R_{i}}\left(\tilde{\pi}_{R_{i}}\left(m_{i}, s_{i}\right)\right)$ is a jointly concave function on $\left(m_{i}, s_{i}\right)$ if $B_{i}>0()$. Therefore, from $B_{1}, B_{2}>0$, it follows that the first order conditions of $u_{R_{i}}\left(\tilde{\pi}_{R_{i}}\left(m_{i}, s_{i}\right)\right)$ and $u_{M_{i}}\left(\tilde{\pi}_{M_{i}}\left(w_{i}\right)\right)$ give the unique Nash equilibrium solution. The first order conditions of manufacturer and retailer's utility functions in chain $i, j, i \neq j$ are as follows

$$
\begin{aligned}
& \partial u_{R_{i}}\left(\tilde{\pi}_{R_{i}}\left(m_{i}, s_{i}\right)\right) / \partial m_{i}=\bar{a}_{i}-2\left(1+\lambda_{R_{i}} \sigma_{0 i}^{2}\right) m_{i}-w_{i}+d m_{j}+d w_{j}+\beta s_{i}-\gamma s_{j}=0, \\
& \partial u_{R_{i}}\left(\tilde{\pi}_{R_{i}}\left(m_{i}, s_{i}\right)\right) / \partial s_{i}=\beta m_{i}-\eta_{i} s_{i}=0, \\
& \partial u_{M_{i}}\left(\tilde{\pi}_{M_{i}}\left(w_{i}\right)\right) / \partial w_{i}=\bar{a}_{i}+\left(1+2 \lambda_{M_{i}} \sigma_{0 i}^{2}\right) c_{i}-m_{i}-2\left(1+\lambda_{M_{i}} \sigma_{0 i}^{2}\right) w_{i}+d m_{j}+d w_{j}+\beta s_{i}-\gamma s_{j}=0 .
\end{aligned}
$$

From Eqs.(A.1)and (A.3), we have

$$
\left(1+2 \lambda_{R_{i}} \sigma_{0 i}^{2}\right) m_{i}=\left(1+2 \lambda_{M_{i}} \sigma_{0 i}^{2}\right)\left(w_{i}-c_{i}\right)
$$

Thus, proposition 1 follows.

\section{Proof of proposition 2}

From Eqs.(A.2)and (A.4), it follows that $s_{i}=\beta m_{i} / \eta_{i}$ and $w_{i}=K_{i} m_{i}+c_{i}$, where $K_{i}=\left(1+2 \lambda_{R_{i}} \sigma_{0 i}^{2}\right) /\left(1+2 \lambda_{M_{i}} \sigma_{0 i}^{2}\right)$. Substituting these equations into Eq.(A.1) yields

$\left(B_{i}+K_{i}+2 \lambda_{R_{i}} \sigma_{0 i}^{2}\right) m_{i}+\left(V_{j}-d K_{j}\right) m_{j}=\bar{a}_{i}-c_{i}+d c_{j}$, for $i, j=1,2, i \neq j$,

where, $B_{i}=2-\beta^{2} / \eta_{i}$ and $V_{i}=\gamma \beta / \eta_{i}-d$. Thus, Nash equilibrium solutions for $m_{1}$ and $m_{2}$ are obtained from solving Eqs. (A.5) simultaneously, which results in Eq.(8) Moreover, Nash equilibrium solution for $w_{i}$ and $s_{i}$ are obtained from $s_{i}^{*}=\beta m_{i}^{*} / \eta_{i}$ and $w_{i}^{*}=K_{i} m_{i}^{*}+c_{i}$ for $i=1,2$.

\section{Proof of proposition 3}

Hessian matrix for $u_{R_{i}}\left(\tilde{\pi}_{R_{i}}\left(m_{i}, s_{i}, M R_{R_{i}}\right)\right)$ is 


$$
H_{R_{i}}=\left[\begin{array}{ccc}
-2\left(1+\frac{\lambda_{R_{i}} \sigma_{0 i}{ }^{2}}{1+\tau_{R_{i}} M R_{R_{i}}}\right) & \beta & \frac{2 \lambda_{R_{i}} \tau_{R_{i}} m_{i} \sigma_{0 i}{ }^{2}}{\left(1+\tau_{R_{i} i} M R_{R_{i}}\right)^{2}} \\
\beta & -\eta_{i} & 0 \\
\frac{2 \lambda_{R_{i}} \tau_{R_{i}} m_{i} \sigma_{0 i}{ }^{2}}{\left(1+\tau_{R_{i} i} M R_{R_{i}}\right)^{2}} & 0 & \frac{-2 \lambda_{R_{i}} \tau_{R_{i}} m_{i} \sigma_{0 i}{ }^{2}}{\left(1+\tau_{R_{i} i} M R_{R_{i}}\right)^{3}}
\end{array}\right], i=1,2 .
$$

Performing elementary Gauss-Jordan operation with using the second and third rows, we have

$$
\left[\begin{array}{ccc}
-2+\frac{\beta^{2}}{\eta_{i}} & 0 & 0 \\
\beta & -\eta_{i} & 0 \\
\frac{2 \lambda_{R_{i}} \tau_{R_{i}} m_{i} \sigma_{0 i}^{2}}{\left(1+\tau_{R_{i} i} M R_{R_{i}}\right)^{2}} & 0 & \frac{-2 \lambda_{R_{i}} \tau_{R_{i}} m_{i} \sigma_{0 i}{ }^{2}}{\left(1+\tau_{R_{i} i} M R_{R_{i}}\right)^{3}}
\end{array}\right], i=1,2 .
$$

From $B_{1}>0$, it follows that all diagonal elements of the matrix are negative, thus Hessian matrix is negative definite and $u_{R_{i}}\left(\tilde{\pi}_{R_{i}}\left(m_{i}, s_{i}, M R_{R_{i}}\right)\right)$ is a concave function on $\left(m_{i}, s_{i}, M R_{R_{i}}\right)$ [5]. The following first order conditions for the manufacturer and retailer profit give the Nash equilibrium solution

$$
\begin{aligned}
& \partial u_{R_{i}}\left(\tilde{\pi}_{R_{i}}\right) / \partial m_{i}=\bar{a}_{i}-2\left(1+\frac{\lambda_{R_{i}} \sigma_{0 i}^{2}}{1+\tau_{R_{i}} M R_{R_{i}}}\right) m_{i}-w_{i}+d m_{j}+d w_{j}+\beta s_{i}-\gamma s_{j}=0, \\
& \partial u_{R_{i}}\left(\tilde{\pi}_{R_{i}}\right) / \partial s_{i}=\beta m_{i}-\eta_{i} s_{i}=0, \\
& \partial u_{R_{i}}\left(\tilde{\pi}_{R_{i}}\right) / \partial M R_{R_{i}}=-1+\frac{\lambda_{R_{i}} \tau_{R_{i}} m_{i}^{2} \sigma_{0 i}^{2}}{\left(1+\tau_{R_{i}} M R_{R_{i}}\right)^{2}}=0 \\
& \partial u_{M_{i}}\left(\tilde{\pi}_{M_{i}}\right) / \partial w_{i}=\bar{a}_{i}+c_{i}-m_{i}-2 w_{i}+d m_{j}+d w_{j}+\beta s_{i}-\gamma s_{j}=0 .
\end{aligned}
$$

From Eq.(A.7) and Eq. (A.10), we obtain $w_{i}-c_{i}=\left(1+\frac{2 \lambda_{R_{i}} \sigma_{0 i}^{2}}{1+\tau_{R_{i}} M R_{R_{i}}}\right) m_{i}$, moreover from Eq.(A.9) and $M R_{R_{i}}, \tau_{R_{i}} \geq 0$, it follows that $m_{i} \sigma_{0 i} \sqrt{\lambda_{R_{i}} \tau_{R_{i}}}=\left(1+\tau_{R_{i}} M R_{R_{i}}\right)$. These two equations give $w_{i}-c_{i}=m_{i}+2 \sqrt{\lambda_{R_{i}} / \tau_{R_{i}}} \sigma_{0 i}$, thus proposition 3 follows.

\section{Proof of proposition 4}

It is straightforward from Eqs. (A.8) and(A.9) that $s_{i}=\beta m_{i} / \eta_{i}$ and $2 m_{i} \sigma_{o i} \sqrt{\lambda_{R_{i}} \tau_{R_{i}}}=\left(1+\tau_{R_{i}} M R_{R_{i}}\right)$, respectively. Inserting these equations as well as $w_{i}=m_{i}+\sqrt{2 \lambda_{R_{i}} / \tau_{R_{i}}} \sigma_{0 i}+c_{i}$ into Eq. (A.7), we obtain

$$
\left(B_{i}+1\right) m_{i}-\left(V_{j}-d\right) m_{j}=\bar{a}_{i}-c_{i}+d c_{j}-4 \sigma_{0 i} \sqrt{\lambda_{R_{i}} / \tau_{R_{i}}}+2 d \sigma_{0 j} \sqrt{\lambda_{R_{j}} / \tau_{R_{j}}} \text { for } i, j=1,2, i \neq j
$$

Solving system of equations (A.11) for $m_{i}$ and $m_{j}$ results in optimal retailer's profit margin (12). Furthermore, the optimal service level, and market research investment, and wholesale price are 
$s_{i}^{*}=\beta m_{i}^{*} / \eta_{i}$, and $M R_{R_{i}}^{*}=\left(m_{i}^{*} \sigma_{o i} \sqrt{\tau_{R_{i}} \lambda_{R_{i}}}-1\right) / \tau_{R_{i}}$, and $w_{i}^{*}=m_{i}^{*}+2 \sqrt{\lambda_{R_{i}} / \tau_{R_{i}}} \sigma_{0 i}+c_{i}$, respectively. Thus proposition 4 follows.

\section{Proof of proposition 5}

Derivative of $m_{i}^{*}$ with respect to $\lambda_{R_{i}}$ and $\lambda_{R_{j}}$ gives

$$
\begin{aligned}
& \frac{\partial m_{i}^{*}}{\partial \lambda_{R_{i}}}=\frac{-2\left(B_{j}+1\right)-d\left(V_{j}-d\right)}{\left(B_{i}+1\right)\left(B_{j}+1\right)-\left(V_{i}-d\right)\left(V_{j}-d\right)}\left(\frac{\sigma_{0 i}}{\sqrt{\lambda_{R_{i}} \tau_{R_{i}}}}\right) \\
& \frac{\partial m_{i}^{*}}{\partial \lambda_{R_{j}}}=\frac{\partial w_{i}^{*}}{\partial \lambda_{R_{j}}}=\frac{d\left(B_{j}+1\right)+2\left(V_{j}-d\right)}{\left(B_{i}+1\right)\left(B_{j}+1\right)-\left(V_{i}-d\right)\left(V_{j}-d\right)}\left(\frac{\sigma_{0 j}}{\sqrt{\lambda_{R_{j}} \tau_{R_{j}}}}\right)
\end{aligned}
$$

The signs of these two deviations depend on the sign of thefirst parts. Define

$$
f(d)=\left(B_{i}+1\right)\left(B_{j}+1\right)-\left(V_{i}-d\right)\left(V_{j}-d\right)=-4 d^{2}+2 \gamma \beta\left(\frac{\eta_{i}+\eta_{j}}{\eta_{i} \eta_{j}}\right) d+\left(B_{i}+1\right)\left(B_{j}+1\right)-\frac{\gamma^{2} \beta^{2}}{\eta_{i} \eta_{j}} .
$$

$f(d)$ is a concave function on $d$, thus roots $d_{ \pm}^{(1)}$ exist as the follows,

$$
d_{ \pm}^{(1)}=\frac{\gamma \beta}{4}\left(\frac{\eta_{i}+\eta_{j}}{\eta_{i} \eta_{j}}\right) \pm \frac{1}{4} \sqrt{\gamma^{2} \beta^{2}\left(\frac{\eta_{i}+\eta_{j}}{\eta_{i} \eta_{j}}\right)^{2}+4\left(\frac{\gamma \beta}{2}+\left(B_{i}+1\right)\left(B_{j}+1\right)\right)}
$$

$f(d)$ is positive on $\left[\max \left\{0, d_{ \pm}^{(1)}\right\}, \min \left\{1, d_{ \pm}^{(1)}\right\}\right]$. On the other hand, from $B_{j}=2-\beta^{2} / \eta_{j}>0$ and $0<\gamma<\beta$ , it follows that $-2\left(B_{j}+1\right)<-2$ and $-2 d<V_{j}-d=\gamma \beta / \eta_{j}-2 d<2-2 d$. Therefore, we have $-d(2-2 d)<-d\left(V_{j}-d\right)<2 d^{2}$. Moreover, from $0<d<1$, it is straightforward that $-2\left(B_{j}+1\right)-d\left(V_{j}-d\right)<0$. Consequently, $\operatorname{sign}\left(\partial m_{i}^{*} / \partial \lambda_{R_{i}}\right)=\operatorname{sign}\left(\partial s_{i}^{*} / \partial \lambda_{R_{i}}\right)=-\operatorname{sign}(f(d))$.

Furthermore, from proposition 3, we know that $w_{i}^{*}=m_{i}^{*}+2 \sqrt{\lambda_{R_{i}} / \tau_{R_{i}}} \sigma_{0 i}+c_{i}$; therefore, derivative $w_{i}^{*}$ with respect to $\lambda_{R_{i}}$ leads to

$$
\frac{\partial w_{i}^{*}}{\partial \lambda_{R_{i}}}=\frac{\partial m_{i}^{*}}{\partial \lambda_{R_{i}}}+\frac{\sigma_{0 i}}{\sqrt{\lambda_{R_{i}} \tau_{R_{i}}}}=\frac{\left(B_{i}-1\right)\left(B_{j}+1\right)-V_{i}\left(V_{j}-d\right)}{\left(B_{i}+1\right)\left(B_{j}+1\right)-\left(V_{i}-d\right)\left(V_{j}-d\right)}\left(\frac{\sigma_{0 i}}{\sqrt{\lambda_{R_{i}} \tau_{R_{i}}}}\right)
$$

Once again define

$$
g(d)=\left(B_{i}-1\right)\left(B_{j}+1\right)-V_{i}\left(V_{j}-d\right)=-2 d^{2}+\gamma \beta\left(\frac{\eta_{i}+2 \eta_{j}}{\eta_{i} \eta_{j}}\right) d+\left(B_{i}-1\right)\left(B_{j}+1\right)-\frac{\gamma^{2} \beta^{2}}{\eta_{i} \eta_{j}}
$$

$g(d)$ is a concave function on $d$, thus if roots $d_{+}^{(2)}$ exist as follows,

$$
d_{ \pm}^{(2)}=\frac{\gamma \beta}{4}\left(\frac{\eta_{i}+2 \eta_{j}}{\eta_{i} \eta_{j}}\right) \pm \frac{1}{4} \sqrt{\gamma^{2} \beta^{2}\left(\frac{\eta_{i}+2 \eta_{j}}{\eta_{i} \eta_{j}}\right)^{2}+4\left(\frac{\gamma \beta}{2}+\left(B_{i}-1\right)\left(B_{j}+1\right)\right)},
$$


then $g(d)$ is positive on $\left[\max \left\{0, d_{ \pm}^{(2)}\right\}, \min \left\{1, d_{ \pm}^{(2)}\right\}\right]$. We know that $\partial w_{i}^{*} / \partial \lambda_{R_{i}}>0$, if $f(d)>0$ and $g(d)>0$, therefore $\max \left\{0, d_{ \pm}^{(1)}\right\}<d<\min \left\{1, d_{ \pm}^{(1)}\right\} \quad$ and $\quad \max \left\{0, d_{ \pm}^{(2)}\right\}<d<\min \left\{1, d_{ \pm}^{(2)}\right\}$ ensure that $\partial w_{i}^{*} / \partial \lambda_{R_{i}}>0$. Therefore, part 1 of proposition 5 follows.

In Eq. (A.13), if $d \in\left(\max \left\{0, d_{-}\right\}, \min \left\{1, d_{+}\right\}\right)$, then $d\left(B_{j}+1\right)+2\left(V_{j}-d\right)$ specifies the sign of $\partial m_{i}^{*} / \partial \lambda_{R_{j}}$. i.e. if $d<2 \gamma \beta /\left(\eta_{i}+\beta^{2}\right)$ and $d \in\left(\max \left\{0, d_{-}\right\}, \min \left\{1, d_{+}\right\}\right)$, then $\partial m_{i}^{*} / \partial \lambda_{R_{j}}, \partial s_{i}^{*} / \partial \lambda_{R_{j}},>0$. Thus, part 2 of proposition 5 follows.

Proof of proposition 6. Hessian matrix for $u_{M_{i}}\left(\tilde{\pi}_{M_{i}}\left(w_{i}, M R_{M_{i}}\right)\right)$ is

$$
H_{M_{i}}=\left[\begin{array}{cc}
-2\left(1+\frac{\lambda_{M_{i}} \sigma_{0 i}^{2}}{1+\tau_{M_{i}} M R_{M_{i}}}\right) & \frac{2 \lambda_{M_{i}} \tau_{M_{i}}\left(w_{i}-c_{i}\right) \sigma_{0 i}^{2}}{\left(1+\tau_{M_{i}} M R_{M_{i}}\right)^{2}} \\
\frac{2 \lambda_{M_{i}} \tau_{M_{i}}\left(w_{i}-c_{i}\right) \sigma_{0 i}^{2}}{\left(1+\tau_{M_{i}} M R_{M_{i}}\right)^{2}} & \frac{-2 \lambda_{M_{i}} \tau_{M_{i}}^{2}\left(w_{i}-c_{i}\right)^{2} \sigma_{0 i}^{2}}{\left(1+\tau_{M_{i}} M R_{M_{i}}\right)^{3}}
\end{array}\right], i=1,2 .
$$

All diagonal elements of the matrix are negative; moreover, $\operatorname{det}\left(H_{M_{i}}\right)=\frac{4 \lambda_{M_{i}} \tau_{R_{i}}^{2}\left(w_{i}-c_{i}\right)^{2} \sigma_{0 i}^{2}}{\left(1+\tau_{M_{i}} M R_{M_{i}}\right)^{3}}>0$. Therefore, Hessian matrix is negatively definite and $u_{M_{i}}\left(\tilde{\pi}_{M_{i}}\left(w_{i}, M R_{M_{i}}\right)\right)$ is a concave function on $\left(w_{i}, M R_{M_{i}}\right)$. Similar to Proposition 1, it can be followed that $u_{R_{i}}\left(\tilde{\pi}_{R_{i}}\left(m_{i}, s_{i}\right)\right)$ is a concave function on $\left(m_{i}, s_{i}\right)$, if and only if we have $B_{i}>0$. The first order conditions for $i, j=1,2, i \neq j$ are

$$
\begin{aligned}
& \partial u_{R_{i}}\left(\tilde{\pi}_{R_{i}}\right) / \partial m_{i}=\bar{a}_{i}-2 m_{i}-w_{i}+d m_{j}+d w_{j}+\beta s_{i}-\gamma s_{j}=0, \\
& \partial u_{R_{i}}\left(\tilde{\pi}_{R_{i}}\right) / \partial s_{i}=\beta m_{i}-\eta_{i} s_{i}=0, \\
& \partial u_{M_{i}}\left(\tilde{\pi}_{M_{i}}\right) / \partial w_{i}=\bar{a}_{i}+c_{i}-m_{i}-2 w_{i}+d m_{j}+d w_{j}+\beta s_{i}-\gamma s_{j}-\frac{2 \lambda_{M_{i}}\left(w_{i}-c_{i}\right) \sigma_{0 i}^{2}}{1+\tau_{M_{i}} M R_{M_{i}}}=0, \\
& \partial u_{M_{i}}\left(\tilde{\pi}_{M_{i}}\right) / \partial M R_{R_{i}}=-1+\frac{\lambda_{M_{i}} \tau_{M_{i}}\left(w_{i}-c_{i}\right)^{2} \sigma_{0 i}^{2}}{\left(1+\tau_{M_{i}} M R_{M_{i}}\right)^{2}}=0 .
\end{aligned}
$$

From Eq. (A.18) and Eq. (A.20), we obtain $\left(w_{i}-c_{i}\right)\left(1+\frac{2 \lambda_{M_{i}} \sigma_{0 i}^{2}}{1+\tau_{M_{i}} M R_{M_{i}}}\right)=m_{i}$. Furthermore, from Eq. (A.21) and $M R_{M_{i}}>0$, it follows that $\sqrt{\lambda_{M_{i}} \tau_{M_{i}}}\left(w_{i}-c_{i}\right) \sigma_{0 i}=\left(1+\tau_{M_{i}} M R_{M_{i}}\right)$. These two recent equations result in $\left(w_{i}-c_{i}\right)+2 \sqrt{\lambda_{M_{i}} / \tau_{M_{i}}} \sigma_{0 i}=m_{i}$. Therefore, proposition 6 follows.

\section{Proof of proposition 7}

Inserting $s_{i}=\beta m_{i} / \eta_{i}, \sqrt{\lambda_{M_{i}} \tau_{M_{i}}}\left(w_{i}-c_{i}\right) \sigma_{0 i}=\left(1+\tau_{M_{i}} M R_{M_{i}}\right)$, and $\left(w_{i}-c_{i}\right)+2 \lambda_{M_{i}} \sqrt{\lambda_{M_{i}} / \tau_{M_{i}}} \sigma_{0 i}=m_{i}$ into Eq. (A.22) and after some manipulations, we have 
$\left(B_{i}+1\right) m_{i}-\left(V_{j}-d\right) m_{j}=\bar{a}_{i}-c_{i}+d c_{j}+2 \sigma_{0 i} \sqrt{\lambda_{M_{i}} / \tau_{M_{i}}}-2 d \sigma_{0 j} \sqrt{\lambda_{M_{j}} / \tau_{M_{j}}}$ for $i, j=1,2, i \neq j$.

Nash equilibrium is achieved by solving system of equations (A.22) for $m_{i}$ and $m_{j}$, which results in the optimal retailer's profit margin (15). Furthermore, the optimal service level, and market research investment, and wholesale price are $s_{i}^{*}=\beta m_{i}^{*} / \eta_{i}$, and $M R_{M_{i}}^{*}=\left(\left(w_{i}^{*}-c_{i}\right) \sigma_{o i} \sqrt{\lambda_{M_{i}} \tau_{M_{i}}}-1\right) / \tau_{M_{i}}$, and $w_{i}^{*}=m_{i}^{*}-2 \sqrt{\lambda_{M_{i}} / \tau_{M_{i}}} \sigma_{0 i}+c_{i}$, respectively . Therefore, proposition 6 follows. $\square$

Proof of proposition 8. Derivative of $m_{i}^{*}$ with respect to $\lambda_{M_{i}}$ and $\lambda_{M_{j}}$ gives

$$
\begin{aligned}
& \frac{\partial m_{i}^{*}}{\partial \lambda_{M_{i}}}=\frac{\left(B_{j}+1\right)+d\left(V_{j}-d\right)}{\left(B_{i}+1\right)\left(B_{j}+1\right)-\left(V_{i}-d\right)\left(V_{j}-d\right)}\left(\frac{\sigma_{0 i}}{\sqrt{\lambda_{M_{i}} \tau_{M_{i}}}}\right) \\
& \frac{\partial m_{i}^{*}}{\partial \lambda_{M_{j}}}=\frac{\partial w_{i}^{*}}{\partial \lambda_{M_{j}}}=\frac{-d\left(B_{j}+1\right)-\left(V_{j}-d\right)}{\left(B_{i}+1\right)\left(B_{j}+1\right)-\left(V_{i}-d\right)\left(V_{j}-d\right)}\left(\frac{\sigma_{0 j}}{\sqrt{\lambda_{M_{i}} \tau_{M_{j}}}}\right)
\end{aligned}
$$

Moreover, from $w_{i}^{*}=m_{i}^{*}-2 \sqrt{\lambda_{M_{i}} / \tau_{M_{i}}} \sigma_{0 i}+c_{i}$, we obtain

$$
\frac{\partial w_{i}^{*}}{\partial \lambda_{M_{i}}}=\frac{\partial m_{i}^{*}}{\partial \lambda_{M_{i}}}-\frac{\sigma_{0 i}}{\sqrt{\lambda_{R_{i}} \tau_{R_{i}}}}=\frac{-B_{i}\left(B_{j}+1\right)+V_{i}\left(V_{j}-d\right)}{\left(B_{i}+1\right)\left(B_{j}+1\right)-\left(V_{i}-d\right)\left(V_{j}-d\right)}\left(\frac{\sigma_{0 i}}{\sqrt{\lambda_{M_{i}} \tau_{M_{i}}}}\right)
$$

Similar to proposition 5, condition $\max \left\{0, d_{ \pm}^{(1)}\right\}<d<\min \left\{1, d_{ \pm}^{(1)}\right\}$ ensures that denominators of all above fractions be positive, therefore sign of Eq. (A.23) and Eq. (A.24) depends on sign of their numerators. Consequently, $\partial m_{i}^{*} / \partial \lambda_{M_{i}}>0$ if $B_{j}>-1-d\left(V_{j}-d\right)$. In proof of proposition 5 , we showed that $-2 d<V_{j}-d<2-2 d$. These inequalities result in $-1-d(2-2 d)<-1-\left(V_{j}-d\right)<-1+2 d^{2}$. Thus, $-1-\left(V_{j}-d\right)$ may be positive only if $\sqrt{0.5}<d<1$, and $\partial m_{i}^{*} / \partial \lambda_{M_{i}}>0$ holds for $0<d<\sqrt{0.5}$. All other terms of part 1 and 2 follow akin to proposition 5 .

\section{Proof of proposition 9}

Hessian matrixes for $u_{R_{i}^{a}}\left(\tilde{\pi}_{R_{i}^{a}}\left(m_{i}^{a}, s_{i}^{a}, M R_{R_{i}^{a}}\right)\right)$ and $u_{M_{j}^{a}}\left(\tilde{\pi}_{M_{j}^{a}}\left(w_{j}^{a}, M R_{M_{j}^{a}}\right)\right)$ are similar to Hessian matrixes in propositions 3 and 6 . We showed that these matrices are negatively definited. Therefore, all value functions are concave, if $B_{i}, B_{j}>0$ and the first order conditions give Nash equilibrium for horizontal and vertical competitions. First order condition for chain $i$ is akin to proposition 3, consequently we have $m_{i}^{a^{*}}+2 \sigma_{0 i} \sqrt{\lambda_{R_{i}} / \tau_{R_{i}}}=\left(w_{i}^{n^{*}}-c_{i}\right)$. Furthermore, due to similarity between the first order conditions for chain $j$ and proposition 6 , it is straightforward that $m_{j}^{n^{*}}=\left(w_{j}^{a^{*}}-c_{j}\right)+2 \sigma_{0 j} \sqrt{\lambda_{M_{j}} / \tau_{M_{j}}}$. Thus, proposition 9 follows.

\section{Proof of proposition 10}

Similar to propositions 4 and 7, It is obvious from the first order conditions of players that $w_{i}^{n}=m_{i}^{a}+2 \sigma_{0 i} \sqrt{\lambda_{R_{i}} / \tau_{R_{i}}}+c_{i}, \quad w_{j}^{a}=m_{j}^{n}-2 \sigma_{0 j} \sqrt{\lambda_{M_{j}} / \tau_{M_{j}}}+c_{j}, \quad s_{i}^{a}=\beta m_{i}^{a} / \eta_{i}, \quad s_{j}^{n}=\beta m_{j}^{n} / \eta_{j}$, 
$M R_{R_{i}}^{a}=\left(m_{i}^{a} \sigma_{0 i} \sqrt{\tau_{R_{i}} \lambda_{R_{i}}}-1\right) / \tau_{R_{i}}$, and $M R_{M_{j}}^{a}=\left(\left(w_{j}^{a}-c_{j}\right) \sigma_{0 j} \sqrt{\tau_{M_{j}} \lambda_{M_{j}}}-1\right) / \tau_{M_{j}}$. By substituting these equations into derivative of retailer $i$ value function with respect to his own profit margin, and after some manipulations, we have

$$
\left(B_{i}+1\right) m_{i}^{a}-\left(V_{j}-d\right) m_{j}^{n}=\bar{a}_{i}-c_{i}+d c_{j}-4 \sigma_{0 i} \sqrt{\lambda_{R_{i}} / \tau_{R_{i}}}-2 d \sigma_{0 j} \sqrt{\lambda_{M_{j}} / \tau_{M_{j}}} .
$$

Moreover, by substituting above equations into derivative of retailer $j$ value function with respect to his own profit margin, and after some manipulations, we obtain

$$
\left(B_{j}+1\right) m_{j}^{n}-\left(V_{i}-d\right) m_{i}^{a}=\bar{a}_{j}-c_{j}+d c_{i}+2 \sigma_{0 j} \sqrt{\lambda_{M_{j}} / \tau_{M_{j}}}+2 d \sigma_{0 j} \sqrt{\lambda_{R_{i}} / \tau_{R_{i}}} .
$$

Solving (A.26) and (A.27) for $m_{i}^{a}$ and $m_{j}^{n}$ yield optimal profit margins of Eq. (20) and Eq. (21). Consequently, proposition 10 follows.

\section{Proof of proposition 11}

Derivative of $m_{i}^{a^{*}}$ with respect to $\lambda_{M_{i}}$ and derivative of $m_{j}^{n^{*}}$ with respect to $\lambda_{M_{j}}$ yield

$$
\begin{gathered}
\frac{\partial m_{i}^{a^{*}}}{\partial \lambda_{R_{i}}}=\frac{-2\left(B_{j}+1\right)-d\left(V_{j}-d\right)}{\left(B_{i}+1\right)\left(B_{j}+1\right)-\left(V_{i}-d\right)\left(V_{j}-d\right)}\left(\frac{\sigma_{0 i}}{\sqrt{\lambda_{R_{i}} \tau_{R_{i}}}}\right), \\
\frac{\partial m_{j}^{n^{*}}}{\partial \lambda_{M_{j}}}=\frac{\left(B_{j}+1\right)+d\left(V_{j}-d\right)}{\left(B_{i}+1\right)\left(B_{j}+1\right)-\left(V_{i}-d\right)\left(V_{j}-d\right)}\left(\frac{\sigma_{0 j}}{\sqrt{\lambda_{M_{j}} \tau_{M_{j}}}}\right)
\end{gathered}
$$

Moreover, from $w_{i}^{n^{*}}=m_{i}^{a^{*}}+2 \sigma_{0 i} \sqrt{\lambda_{R_{i}} / \tau_{R_{i}}}+c_{i}$ and $w_{j}^{a^{*}}=m_{j}^{n^{*}}-2 \sigma_{0 j} \sqrt{\lambda_{M_{j}} / \tau_{M_{j}}}+c_{j}$, we obtain

$$
\begin{aligned}
& \frac{\partial w_{i}^{n^{*}}}{\partial \lambda_{R_{i}}}=\frac{\partial m_{i}^{a^{*}}}{\partial \lambda_{R_{i}}}+\frac{\sigma_{0 i}}{\sqrt{\lambda_{R_{i}} \tau_{R_{i}}}}=\frac{\left(B_{i}-1\right)\left(B_{j}+1\right)-V_{i}\left(V_{j}-d\right)}{\left(B_{i}+1\right)\left(B_{j}+1\right)-\left(V_{i}-d\right)\left(V_{j}-d\right)}\left(\frac{\sigma_{0 i}}{\sqrt{\lambda_{R_{i}} \tau_{R_{i}}}}\right), \\
& \frac{\partial w_{j}^{a^{*}}}{\partial \lambda_{M_{j}}}=\frac{\partial m_{j}^{n^{*}}}{\partial \lambda_{M_{j}}}-\frac{\sigma_{0 j}}{\sqrt{\lambda_{M_{j}} \tau_{M_{j}}}}=\frac{-B_{j}\left(B_{i}+1\right)+V_{i}\left(V_{j}-d\right)}{\left(B_{i}+1\right)\left(B_{j}+1\right)-\left(V_{i}-d\right)\left(V_{j}-d\right)}\left(\frac{\sigma_{0 j}}{\sqrt{\lambda_{M_{j}} \tau_{M_{j}}}}\right)
\end{aligned}
$$

Profit margins of partners in one chain change with respect to risk sensitivity of the rival as follows

$$
\begin{aligned}
& \frac{\partial m_{i}^{a^{*}}}{\partial \lambda_{M_{j}}}=\frac{\partial w_{i}^{n^{*}}}{\partial \lambda_{M_{i}}}=\frac{-d\left(B_{j}+1\right)+\left(V_{j}-d\right)}{\left(B_{i}+1\right)\left(B_{j}+1\right)-\left(V_{i}-d\right)\left(V_{j}-d\right)}\left(\frac{\sigma_{0 j}}{\sqrt{\lambda_{M_{j}} \tau_{M_{j}}}}\right), \\
& \frac{\partial w_{j}^{a^{*}}}{\partial \lambda_{R_{i}}}=\frac{\partial m_{j}^{n^{*}}}{\partial \lambda_{R_{i}}}=\frac{\left(B_{j}+1\right)+2\left(V_{j}-d\right)}{\left(B_{i}+1\right)\left(B_{j}+1\right)-\left(V_{i}-d\right)\left(V_{j}-d\right)}\left(\frac{\sigma_{0 i}}{\sqrt{\lambda_{R_{i}} \tau_{R_{i}}}}\right) .
\end{aligned}
$$

Akin to propositions 5 and 8, all conclusions in parts 1 and part 2 of this proposition follow from $\mathrm{A}(30)-\mathrm{A}(33)$. 


\section{References}

Agrawal, V., \& Seshadri, S. (2000). Risk intermediation in supply chains. IIE Transaction, 32(9), 819-831.

Allon, G., \& Federgruen, A. (2007). Competition in service industries. Operation Research, 55(1), 37-55.

Bar-Shira, Z., \& Finkelshtain, I. (1999). Two-moments decision models and utility-representable preferences. Journal of Economic Behavior Organization, 38(2), 237-244.

Basuroy, S., \& Nguyen, D.(1998). Multinomial logit market share models: Equilibrium characteristics and strategic implications. Management Science, 44(10),1396-1404.

Bazaraa, M.S., Sherali, H.D., \& Shetty, C.M. (2006). Nonlinear Programming: Theory and algorithms.New Jersey: John Wily and Sons.

Beckmann, M.J., \& Funke, U.H. (1978). Product attraction, advertising and sales: Towards a utility model of market behavior. Mathematical Method Operation Research, 22(1), 1-11.

Bell, D.E., Keeney, R.L., \& Little, J.D.C. (1975).A market share theorem. Journal of Marketing Research, 12,136-141.

Bernstein, F., \& Federgruen, A. (2007).Coordination mechanisms for supply chains under price and service competition. Manufacturing \&Service Operations Management, 9(3), 242-262.

Bernstein, F., \& Federgruen, A. (2004).A general equilibrium model for industries with price and service competition. Operations Research, 52 (6), 868-886.

Cachon, G.P., \& Netessine, S. (2003). Game theory in supply chain analysis, in: Simchi-Levi, D., Wu S.D.,\&Shen Z.(Eds) Handbook of Quantitative Supply Chain Analysis: Modeling in the ebusiness. Kluwer Academic Publishers, Boston, 1-14,

Chopra, S., \& Meindl, P. (2007). Supply Chain Management, Strategy, Planning, and Operations. New York:Prince Hall.

Cooper, L.G. (1993). Market-Share Models, in: Eliashberg, J.,Lillien, G.L.,(Eds), Handbooks of Operations Research and Management Science. Elsevier Science Publishers, Amsterdam, 257-313.

Gallego, G., Huh, W.T., Kang W.,\& Phillips, R.(2006).Price competition with the attraction demand model: Existence of unique equilibrium and its stability. Manufacturing \& Service Operations Management, 8(4), 359-375.

Gan, X.H., Sethi, S.P., \& Yan, H.M. (2005). Channel coordination with a risk-neutral supplier and a downside-risk-averse retailer. Production and Operations Management, 14(1), 80-89.

Ganeshan, R., Jake, E., Magazin, M.J., \& Stephens, P. (1998). A taxonomic review of supply chain management research, in:Tayur, S., Ganeshan, R.,\& Magazine, M.J. (Eds) Quantitative models for supply chain management, New York, Springer-Velag, LLC.

Gilbert, S.M., \& Cvsa, V. (2003). Strategic commitment to price to stimulate downstream innovation in a supply chain. European Journal of Operational Research, 150,617-639.

Gruca, T.S., \& Sudharshan, D.(1991). Equilibrium characteristics of multinomial logit market share models. Journal of Marketing Research, 28, 480-482.

He, X., Prasad, A., Sethi, S.P., \& Gutierrez, G.J.(2007). A survey of stackelberg differential game model in supply and marketing channels. Journal of System Science and System Engineering,16, 385-413.

Koltler,P., \& Keller, K.L. (2006). Marketing Management. New Jersey Pearson: Prentice Hall.

Kogan, K., \& Tapiero, C.S. (2007). Supply Chain Games, Operations Management, and Risk Valuation.New York: Springer.

Leeflang, P.S.H. (2008). Modeling Competitive Responsiveness, in:Wierenga, B.(Ed.) Handbook of marketing decision models. International series in operation research \& management science, Springer science.

Leng, M., \& Parlar, M. (2005). Game theoretic applications in supply chain management: A review. INFOR, 43 (3), 187-220.

Mariampolski, H. (2001). Qualitative Market Research: A Comprehensive Guide. SAGA, California: Thousand Oaks. 
Mesak, H.I., \& Means,T .(1998). Modeling advertising budgeting and allocation decisions using modified multinomial logit market share models. Journal ofthe Operational Research Society. 49,1260-1269.

Monahan,G.E. (1987). The structure of equilibria in market share attraction models. Management Science, 33(2), 228-243.

Tsay, A.A. (2002). Risk sensitivity in distribution channel partnerships: implications for manufacturer return policies. Journal of Retailing, 78(2), 147-160.

Tsay, A.A., \& Agrawal, N. (2000). Channel dynamics under price and service competition. Manufacturing \& Service Operations Management, 2(4), 372- 391.

Wu, C., Petruzzi, N.C., \& Chhajed, D. (2007). Vertical integration with price-setting competitive newsvendors. Decision Sciences, 38(4), 581-610.

Xiao, T.J., \& Yang, D.Q. (2008).Price and service competition of supply chains with risk-averse retailers under demand uncertainty. International Journal of Production Economics, 114(1),187200.

Xiao, T.J., \& Yang, D.Q. (2009). Risk sharing and information revelation mechanism of a onemanufacturer and one retailer supply chain facing an integrated competitor. European Journal of Operational Research,196,1076-1085.

Yang, D., Xiao, T., \& Shen, H. (2009).Pricing, service level and lot size decisions of a supply chain with risk-averse retailers: implications to practitioners. Production Planning and Control, 20(4), 320-331. 